\title{
Evolution of genital asymmetry, exaggerated eye stalks, and extreme palpal elongation in Panjange spiders (Araneae: Pholcidae)
}

\author{
Bernhard A. HUBER ${ }^{1, *} \&$ Olga M. NUÑEZA ${ }^{2}$ \\ ${ }^{1}$ Alexander Koenig Research Museum of Zoology, Adenauerallee 160, 53113 Bonn, Germany. \\ ${ }^{2}$ Department of Biological Sciences, Mindanao State University - Iligan Institute of Technology, \\ Tibanga, Iligan City 9200, Philippines. \\ *Corresponding author: b.huber@zfmk.de \\ ${ }^{2}$ Email: olgamnuneza@yahoo.com \\ ${ }^{1}$ urn:1sid:zoobank.org:author:33607F65-19BF-4DC9-94FD-4BB88CED455F \\ ${ }^{2}$ urn:Isid:zoobank.org:author:6D14FCCC-F148-4293-9F23-0EB5A4119305
}

\begin{abstract}
We describe several new species of the previously monotypic Panjange lanthana species group from the Philippines and document their extraordinary morphology. Some species show strong male genital asymmetry, a phenomenon that seems to be exceedingly rare in spiders. Males of most species have eye stalks, and in two species these eye stalks are among the longest ever recorded in spiders. Some species show a tendency for male genital (pedipalp) elongation, and one species has the longest and thinnest palps ever recorded in Pholcidae. A cladistic analysis is performed including all described and several undescribed species of Panjange (except for one "problem species"), supporting the lanthana group and its close relationship with members of the possibly paraphyletic cavicola group. The following eight new species are described: Panjange malagos Huber sp. nov.; Pa. casaroro Huber sp. nov.; Pa. camiguin Huber sp. nov.; Pa. hamiguitan Huber sp. nov.; Pa. isarog Huber sp. nov.; Pa. dinagat Huber sp. nov.; Pa. marilog Huber sp. nov.; Pa. bukidnon Huber sp. nov.
\end{abstract}

Key words. Genital asymmetry, eye stalks, palpal elongation, sexual selection, Panjange, Philippines.

Huber B.A. \& Nuñeza O.M. 2015. Evolution of genital asymmetry, exaggerated eye stalks, and extreme palpal elongation in Panjange spiders (Araneae: Pholcidae). European Journal of Taxonomy 169: 1-46. http://dx.doi. org/10.5852/ejt.2015.169

\section{Introduction}

Panjange Deeleman-Reinhold \& Deeleman, 1983 spiders are leaf-dwelling pholcids widely distributed in insular Southeast Asia, from Borneo and the Philippines to northern Australia (Huber 2011). They exhibit some of the most extraordinary morphology among Pholcidae. Males of most species have eye stalks, sometimes with long pointed processes; males of some species have unusually elongated pedipalps, which in spiders function as copulatory organs; and females of some species have external portions of their genitalia strongly folded and extensible (Huber 2011). The biological significances of these sexual modifications remain unclear. 
The genus has long been divided into three species groups: the nigrifrons group on Borneo, the cavicola group ranging from Sulawesi to northern Australia, and the lanthana group in the Philippines (Deeleman-Reinhold \& Platnick 1986; Huber 2011). However, the latter "group" so far consisted of only one species, the very unique type species Panjange lanthana Deeleman-Reinhold \& Deeleman, 1983, known only from the type series from Luzon. No further Panjange species has been known from the Philippines. Here we describe several new species that appear closely related to Pa. lanthana, and that show some very unique morphological features, not only among Pholcidae but among spiders in general: genital asymmetry, exaggerated eye stalks, and extreme palpal elongation.

Genital asymmetry is very common in some arthropod groups (such as insects) but very rare in others (such as spiders) (reviewed in Huber et al. 2007). Ultimately, the reason for this may be the fact that insects have an unpaired median intromittent organ (the aedeagus) while spider males copulate with a pair of pedipalps (Huber 2010). However, while there are plausible evolutionary routes to asymmetry in insects (related to changes in mating position that in turn are driven by sexual selection; Huber 2010), the origin of spider genital asymmetry is still poorly understood. Two of the new species described below are among the most asymmetric spiders known so far.

Eye stalks are also widespread in arthropods such as crustaceans (e.g., Barnes 1968; Bowman 1984; Zeil et al. 1986) and insects (in particular flies: e.g., Burkhardt \& de la Motte 1988; Wilkinson \& Dodson 1997; Baker \& Wilkinson 2001), but very rare in arachnids. Fairly well studied exceptions are certain linyphiid species where the male "head" or ocular area is modified, presumably as a result of sexual selection: males take advantage of the fact that the female mouthparts contact their ocular region during copulation and modify this region in an attempt to manipulate females (e.g., Schaible et al. 1986; Vanacker et al. 2003; Kunz et al. 2012). Usually, these modifications come in the form of low humps or turrets, but rarely also as (unpaired median) stalks, such as in Walckenaeria acuminata Blackwall, 1833. In Pholcidae, a similar mating position may explain the repeated origin of male "head" modifications, such as in the genera Modisimus Simon, 1893, Smeringopina Kraus, 1957, Pholcus Walckenaer, 1805, Leptopholcus Simon, 1893, and Panjange (see e.g., Huber 1997a, 2011, 2013). Two of the new species described below have the longest eye stalks known in Pholcidae, and possibly in spiders.

Elongated male copulatory organs (pedipalps) occur in various spider groups, but the palps are rarely longer than the body (exceptions occur for example in Filistatidae; Marusik \& Zamani 2015). The significance of this elongation is poorly understood, and the plausible idea that long palps may save the male from cannibalism has to our knowledge never been tested. In Pholcidae, palpal strength seems to play an important role, often leading to very thick palpal segments (Huber \& Eberhard 1997). As a result, elongated (and thus necessarily thin) palps are rare in pholcids, and apparently limited to Southeast Asian leaf dwelling species. The only cases known to us occur in the genera Calapnita Simon, 1892 (most notably C. semengoh Huber, 2011), in most species of the Panjange cavicola group (Huber 2011) and in certain species currently placed in Pholcus but possibly close to Panjange (such as Pholcus bohorok Huber, 2011). In all of them, females have extensible external genitalia (or scapes), suggesting a functional correlation between palp length and scape length. A new species described below has by far the longest and thinnest male palps known in Pholcidae, as well as the longest female scape.

\section{Material and methods}

Most of the material studied herein was collected during a recent expedition to the Philippines (Feb.Mar. 2014). Further specimens came from student projects at Mindanao State University - Iligan Institute of Technology dealing with ecological aspects of pholcid diversity in the Philippines. The material is currently deposited at Zoologisches Forschungsmuseum Alexander Koenig, Bonn (ZFMK) and Mindanao State University - Iligan Institute of Technology (MSU-IIT). 
Species descriptions are arranged as in the cladogram in Fig. 1. Methods and terminology are as in recent revisions (Huber 2011, 2013). Measurements are in mm unless otherwise noted. Eye measurements are $+/-5 \mu \mathrm{m}$. Epigyna were cleared in warm $\mathrm{NaOH}$ solution and stained with chlorazol black. For SEM photographs, specimens were dried in HMDS (Brown 1993), and photographed with a Hitachi S-2460 scanning electron microscope. SEM data are presented within the descriptions but are not based on the holotype specimens described. The distribution map was generated with ArcMap 10.0.

The numerical cladistic analyses were done using NONA, version 2 (Goloboff 1993), Pee-Wee, version 2.8 (Goloboff 1997) and TNT, version 1.1 (Goloboff et al. 2004, 2008). The matrix is shown in Appendix 1; terminal taxa and characters scored are given in Appendices 2 and 3. All 26 characters are binary. The final matrix can be downloaded at http://www.pholcidae.de/matrices.html [accessed 21 Nov. 2015]. Cladogram analysis was done with Winclada, version 1.00.08 (Nixon 2002). See "Cladistic analysis" section below for details of the analyses.

\section{Abbreviations}

The following abbreviations are used in the text:

ALE $=$ anterior lateral eyes

ALS $=$ anterior lateral spinnerets

AME $=$ anterior median eyes

a.s.l. $=$ above sea level

$\mathrm{L} / \mathrm{d}=$ length/diameter

PME $=$ posterior median eyes

$\mathrm{PMS}=$ posterior median spinnerets

In order to avoid confusion, Panjange is abbreviated as "Pa."; Pholcus is never abbreviated. Further abbreviations used only in figures are explained directly in the figure legends.

\section{Results}

Class Arachnida Cuvier, 1812

Order Araneae Clerck, 1757

Family Pholcidae C.L. Koch, 1851

Genus Panjange Deeleman-Reinhold \& Deeleman, 1983

Panjange Deeleman-Reinhold \& Deeleman, 1983: 123-124. Type species by original designation: Panjange lanthana Deeleman-Reinhold \& Deeleman, 1983.

Panjange - Deeleman-Reinhold 1986a: 47, fig. 6; 1986b: 220. — Huber 2001: 118-119; 2011: 108-110.

\section{Note on species groups}

Previous work on Panjange has identified three species groups, the nigrifrons group on Borneo, the widespread cavicola group (Sulawesi to northern Australia) and the previously monotypic lanthana group on the Philippines (Deeleman-Reinhold \& Platnick 1986; Huber 2011). The present cladistic analysis largely recovers these three groups, but the cavicola group is considered paraphyletic (Fig. 1).

The present paper focuses on the lanthana group A separate paper on the nigrifrons group is in preparation, as is a molecular phylogeny of the entire genus and of its relationships to other Pholcinae.

\section{Identification key}

This key is primarily designed to identify species groups of Panjange and species of the lanthana group. It mostly works for males and females, but females remain difficult to identify. An examination of the 
cleared internal genitalia may be necessary (step 7); geography rather than morphology may help to separate females (step 2); in one species, the female is unknown (Pa. bukidnon Huber sp. nov.; step 4).

1. Male chelicerae with distal frontal apophyses (fig. 472 in Huber 2011); female epigynal scape short or absent (figs 473, 492 in Huber 2011); known only from Borneo.....

- Male chelicerae without distal frontal apophyses, only with pair of proximal processes (e.g., Figs 17, 40, 66); epigynal scape long and strongly folded (e.g., Figs 22, 36, 67) ....................................... 2

2. Embolus parallel to male bulbal process (appendix); known from Sulawesi to Australia

cavicola group

- Embolus and bulbal appendix pointing in opposite directions (e.g., Figs 18, 64, 69); known from the Philippines only ......

lanthana group...3

3. Eight eyes (AME present; lenses clearly visible in dissecting microscope); without pointed processes arising from male eye triads (fig. 441 in Huber 2011); procursus with two distal hinged processes (figs 436, 437 in Huber 2011).

.Pa. lanthana Deeleman-Reinhold \& Deeleman, 1983

- Six eyes (AME absent; rarely tiny, barely visible in dissecting microscope and apparently nonfunctional: Fig. 45), with pointed processes arising from male eye triads (e.g., Figs 17, 28, 66, 76); procursus with only one distal hinged process

4. Procursus extremely wide and strongly curved (Fig. 91); eye stalks short, with spines contacting each other (Fig. 90); bulbal processes (embolus and appendix) very short (Fig. 91)....

Pa. bukidnon Huber sp. nov.

- Procursus, male ocular area, and bulbal processes different

5. Male palpal segments (distal of trochanter) extremely long (femur about $15 \times$ as long as wide; Figs 64, 65); female epigynal scape extremely long (Fig. 67) ...........Pa. hamiguitan Huber sp. nov.

- Male palpal segments shorter (femur less than $7 \times$ as long as wide; e.g., Figs 19, 25, 39); female epigynal scape shorter (e.g., Figs 22, 29, 72) ......

6. Male clypeus without spines; dorsal tarsal elongation very long (Figs 18, 24); male procursus asymmetric; female epigynal scape directed toward posterior......

- Male clypeus with spines (Figs 71, 76, 81); dorsal tarsal elongation short (Figs 70, 75, 80); male procursus symmetric; female epigynal scape directed toward anterior (Figs $72,77,82$ ) .............. 9

7. Male eye stalks short (Fig. 17); spines on male eye stalks short, not contacting each other; pore plates round (Fig. 23)....

Pa. malagos Huber sp. nov.

- Male eye stalks very long (Figs 28, 35); spines on male eye stalks long, contacting each other (Fig. 49); pore plates oval (Figs 30, 37).

8. Male palpal trochanter with only one long retrolateral apophysis (Fig. 25); male palpal tarsal elongation widening distally (Fig. 24); female epigynal scape with two lobes (Fig. 29)...

Pa. casaroro Huber sp. nov.

- Male palpal trochanter with two short retrolateral apophyses (Fig. 39); male palpal tarsal elongation not widening distally (Fig. 38); female epigynal scape simple (Fig. 36). ..Pa. camiguin Huber sp. nov.

9. Appendix of genital bulb with simple curved tip (Fig. 69); male palpal retrolatero-ventral trochanter apophysis with simple rounded tip (Fig. 70); female epigynal scape without widening (Fig. 72) .....

Pa. isarog Huber sp. nov.

- Appendix of genital bulb with bifid tip (Figs 74, 79); male palpal retrolatero-ventral trochanter apophysis bifid (Figs 75, 80); female epigynal scape with widening (Figs 77, 82) ..... 10 
10. Retrolateral process on procursus massive, with parallel ridges (Fig. 75); female internal genitalia with large lateral structures and elongate pore plates (Fig. 78)....

Pa. dinagat Huber sp. nov.

- Retrolateral process on procursus smaller, with two pointed tips (Fig. 80); female internal genitalia without large lateral structures and roundish pore plates (Fig. 83) Pa. marilog Huber sp. nov.

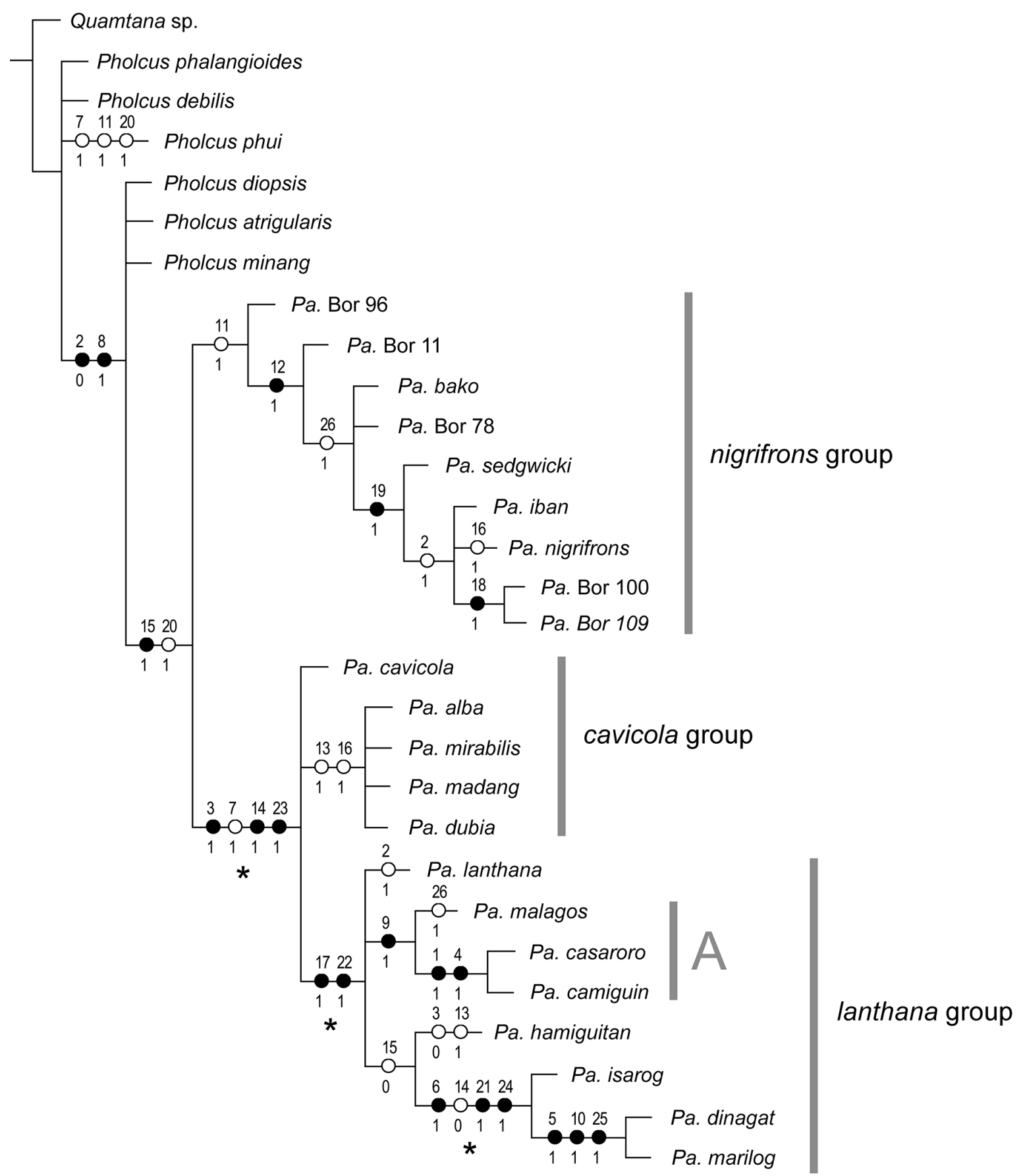

Fig. 1. Strict consensus of two most parsimonious cladograms of Panjange Deeleman-Reinhold \& Deeleman, 1983 resulting from analyses of the matrix in Appendix 1 using equal character weights, successive weighting, and implicit enumeration. Only unambiguous character changes are shown. $\mathrm{A}=$ clade with asymmetric male palps; ${ }^{*}=$ positions of Pa. bukidnon Huber sp. nov. in preliminary cladistic analyses. See Cladistic analysis section for further details. 


\section{Cladistic analysis}

Preliminary analyses including all available species of Panjange (all 18 described species plus five undescribed species) revealed that the highly aberrant Pa. bukidnon Huber sp. nov. was also the most difficult to place in the cladogram. It ended up at three different positions, resulting in many trees and a consensus with large polytomies. For this reason, Pa. bukidnon Huber sp. nov. was deleted from the final matrix. It may be correctly placed in the lanthana group but its sister taxon remains unknown (see Monophyly and relationships below).

One potentially informative character system was also largely deleted from the final matrix. The apophyses and processes on the male palpal trochanter come in a wide variety of numbers, shapes and positions, and it seemed impossible to code them in a convincing way. Only one detail was left in the matrix (Appendix 3, character 10).

Using NONA with hold/100, mult*200 (or hold/10; mult*10.000), and amb- for the matrix in Appendix 1 and equal character weights resulted in two most parsimonious cladograms with a length of $37(\mathrm{Ci}=$ 70 ; $\mathrm{Ri}=90$ ). Variation occurred only among outgroup taxa and in the support for the monophyly of Panjange (characters 15 and 20, or only character 20). The cladogram shown in Fig. 1 is the strict consensus of these two cladograms.

Using TNT with the implicit enumeration algorithm resulted in the same two trees, as did successive weighting in NONA (with the consistency index as weighting function). Implied weighting in Pee-Wee (which resolves character conflict in favor of the characters that have less homoplasy) was used with various settings of the constant of concavity K (1-6) to explore the stability of different clades under different weighting regimes. Major differences to the tree shown in Fig. 1 occurred only with $\mathrm{K}=1$ and $\mathrm{K}=2$, which resulted in large polytomies and no support for the monophyly of Panjange. However, even in these trees, the monophyly of the lanthana group was consistently recovered as was its close relationship to the cavicola group. The only difference within the lanthana group concerned the position of Pa. hamiguitan Huber sp. nov., which was not sister to Pa. isarog Huber sp. nov. + (Pa. dinagat Huber sp. nov. + Pa. marilog Huber sp. nov.) but placed in a basal tetrachotomy.

\section{Panjange lanthana group}

\section{Diagnosis}

Males are easily distinguished from congeners in other species groups of Panjange by the unique processes of the genital bulb (embolus and appendix), pointing in opposite directions (Figs 18, 64, 69). Females differ from members of the nigrifrons group by their long folded scapes (Figs 22, 67, 72) but are in general similar to females of the cavicola group. Other leaf-dwelling pholcids in the Philippines differ from Panjange as follows: Calapnita with longer abdomen that is monochromous and dorso-posteriorly not angular; male eyes on very low humps; embolus parallel to bulbal appendix. An undescribed group of leaf-dwelling Pholcus species differs from Philippine Panjange species as follows: dorsal process on procursus; embolus parallel to bulbal appendix; short male eye stalks without pointed processes; and epigynum without long folded scape.

\section{Description}

\section{Male}

Measurements. Total body length $\sim 4.0-5.5$; carapace width $0.9-1.2$; leg 1 length $\sim 30-45$; tibia 1 length $\sim 8.0-10.5$; tibia $2 /$ tibia 4 length 1.10-1.25; tibia 1 L/d $\sim 95-110$. 
Color. In life (Figs 2-15) mostly pale ochre-yellow to whitish, ocular area with brown mark, sternum whitish, legs with dark patellae and tibia-metatarsus joints; abdomen with dark brown to black marks dorsally and laterally, sometimes partly reddish.

Body. Carapace without median furrow; ocular area raised, eye triads on stalks of variable length (e.g., Figs 17, 28, 66, 71), often with pair of additional pointed processes arising from near PME (absent only in $P a$. lanthana). AME usually absent, clearly present only in $P a$. lanthana, present but tiny and barely visible in Pa. camiguin Huber sp. nov. males (Fig. 45). Clypeus high, either unmodified or with $\sim 20-25$ short spines (Figs 84, 85), sometimes in addition to stronger hairs below ocular area (Fig. 84). Abdomen cylindrical, angular above spinnerets (Figs 2,9). Male gonopore with four epiandrous spigots (Figs 60,88 ); each ALS with large widened spigot, pointed spigot, and six cylindrically shaped spigots (of varying sizes; Figs 32, 62); PMS with two spigots each (Fig. 63).

Chelicerae. With only one pair of frontal processes proximally, without distal apophyses (Figs 17, 47, 84); without modified hairs; without stridulatory ridges.

Palps. Coxa usually unmodified, in Pa. hamiguitan Huber sp. nov. and Pa. bukidnon Huber sp. nov. with small ventral apophysis (Figs 65,92 ); trochanter and femur very variable, with species-specific sets of humps, short processes, and more complex apophyses; patella short to longer than wide; tibia with two trichobothria; palpal tarsus usually with whitish dorsal elongation carrying tarsal organ (e.g., Figs 19, 25, 65), rarely short (e.g., Figs 70, 75), absent in Pa. bukidnon Huber sp. nov. (Fig. 92); palpal tarsal organ capsulate (Fig. 89); procursus usually consisting of proximal and distal part connected by membranous hinge (e.g., Figs 18, 64, 80), but not hinged in right palps of asymmetric species; parallel ridges on procursus sometimes distinct (e.g., Figs 18, 26, 52), sometimes indistinct or absent; bulb with strong proximal sclerite (e.g., Figs 18, 69), with two processes pointing in opposite directions: appendix toward ventral, embolus toward dorsal.

LEGS. Without spines, without curved hairs, few vertical hairs; retrolateral trichobothrium very proximal (tibia 1: at $2-4 \%$ of tibia length), prolateral trichobothrium absent on tibia 1, present on other tibiae. Tarsus 1 with $\sim 30$ pseudosegments, sometimes very indistinct; tarsus 4 with single row of ventral combhairs of the Pholcus-type (cf. Huber \& Fleckenstein 2008) (Fig. 58).

\section{Female}

Similar to male but without eye stalks; eye triads on low humps (Fig. 46); clypeus and chelicerae unmodified; legs slightly shorter than in male. Epigynum weakly sclerotized, with more or less long, folded and extensible scape directed either toward posterior or toward anterior (e.g., Figs 22, 36, 72); sometimes widened at about half length (Figs 77, 82). Internal genitalia with pair of pore plates of variable shape.

\section{Monophyly and relationships}

The monophyly of the Pa. lanthana group is consistently supported by two characters: the small ventral process distally on the proximal part of the procursus (character 17; Figs 25, 70), and the unique direction of the embolus, pointing in an opposite direction than the appendix rather than lying parallel to it (character 22; Figs 18, 64, 69).

The closest relatives of the lanthana group are probably members of the $P a$. cavicola group. This relationship has been suggested before (Huber 2011) and is here supported by numerous characters: hooked rather than straight spines in ocular area (character 3; Figs 48, 87); absence of distal cheliceral apophyses (character 7; Figs 17, 47, 66); strong palpal tarsal elongation (character 14; Figs 19, 39, 65); and long strongly folded epigynal scape (character 23; Figs 22, 36, 72). 
Within the lanthana group, the monophyly of three species Pa. malagos Huber sp. nov. $+(P a$. casaroro Huber sp. nov. $+P$ a camiguin Huber sp. nov.) is supported only by the asymmetry of the male procursus (character 9). A second species group, Pa. isarog Huber sp. nov. + (Pa. dinagat Huber sp. nov. $+P a$. marilog Huber sp. nov.) is strongly supported: male clypeus with spines (character 6; Figs 84, 85); male palpal tarsal process secondarily short (character 14; Figs 70, 75, 80); uncus-like process arising from proximal bulbal sclerite (character 21; Figs 70, 80); and epigynal scape directed toward anterior (character 24; Figs 72, 77, 82). The sister taxa of $P a$. lanthana and $P a$. hamiguitan Huber sp. nov. remain unclear. In Fig. 1, Pa. hamiguitan Huber sp. nov. is placed as sister to Pa. isarog Huber sp. nov. + (Pa. dinagat Huber sp. nov. $+P a$. marilog Huber sp. nov.), but this is weakly supported by the secondary reduction of ridges on the procursus and was not recovered in all analyses (see above).

Entirely dubious is the position of $P a$. bukidnon Huber sp. nov. (excluded from the analysis for reasons detailed above; see "Cladistic analysis"). In preliminary analyses including Pa. bukidnon Huber sp. nov., it ended up at three different positions, indicated in Fig. 1 by asterisks: (1) as sister to the lanthana + cavicola groups; (2) as sister to the lanthana group; or (3) as sister to Pa. isarog Huber sp. nov. + (Pa. dinagat Huber sp. nov. + Pa. marilog Huber sp. nov.). It shares one of the synapomorphies of the lanthana group (embolus pointing in opposite direction than appendix) but not the other (ventral process on procursus). The parallel tips of the ocular spines (Fig. 90) remind of Pa. casaroro Huber sp. nov. + Pa. camiguin Huber sp. nov. while the small rounded process between appendix and genital bulb (Fig. 91) reminds of $P a$. dinagat Huber sp. nov. $+P a$. marilog Huber sp. nov. The procursus is highly autapomorphic. It seems that only the discovery of the unknown female and/or molecular data may solve this issue.

\section{Natural history}

Most species seem to have low abundances and very patchy distributions, with few specimens found within a very small area and none in surrounding areas of apparently similar vegetation. This may have been related to the low abundance and patchiness of suitable large leaves. Specimens were usually collected between about $50 \mathrm{~cm}$ above ground to about $2 \mathrm{~m}$, and they are likely to occur also in higher strata of the forest, possibly in higher abundances. The web is a domed sheet, most of which is closely attached to the underside of a leaf. The extremely fine silk is poorly visible except when the sheet is viewed directly from the side. Egg sacs are only slightly elongated and covered by a barely visible layer of silk (Figs 3, 8, 12). In one case (Pa. camiguin Huber sp. nov.; Fig. 8), eight of ten eggs in an egg sac were parasitized by a parasitic wasp.

\section{Composition}

As construed here, the Panjange lanthana group now contains nine species (including the dubious $P a$. bukidnon Huber sp. nov.). Judging from known distribution patterns and from the large number of poorly sampled islands, the group may well contain several times as many species.

\section{Distribution}

Known from the Philippines only (Fig. 16).

Panjange lanthana Deeleman-Reinhold \& Deeleman, 1983

Figs 2-4

Panjange lanthana Deeleman-Reinhold \& Deeleman, 1983: 124, figs 1-9 (ぷ゚).

Panjange lanthana - Huber 2011: 111-114, figs 436-58, 765-66, 786, 788 (う゚ㅇ). 

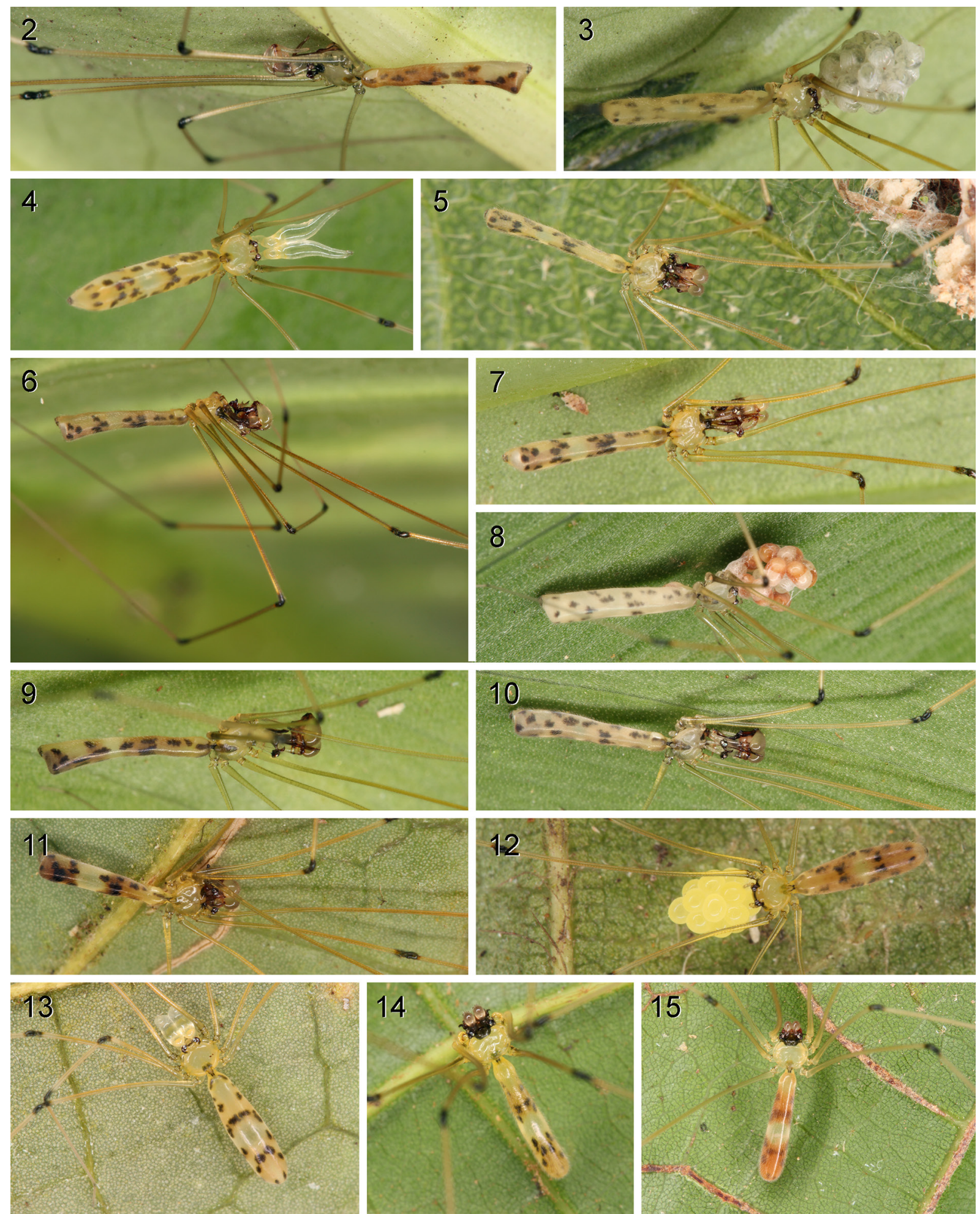

Figs 2-15. Live specimens. 2-4. Pa. lanthana, Mt. Isarog, $\partial^{\lambda}, ~+q$ with eggsac, and penultimate ${ }^{\lambda}$. 5. $P a$.

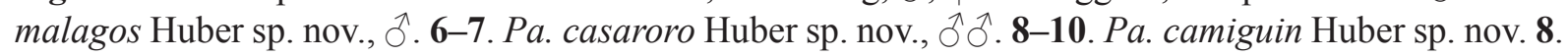
$\uparrow$ with parasitized eggsac, from Camiguin Island. 9. $\widehat{\partial}$ from Bohol Island. 10. $\widehat{\delta}$ from Camiguin Island. 11-13. Pa. dinagat Huber sp. nov., $\partial^{\lambda}, q$ with eggsac, and penultimate ${ }^{\lambda}$. 14-15. Pa. marilog Huber sp. nov., $\widehat{\partial} \widehat{\partial}$ showing color variation. 


\section{Note}

Previously, the type species $P$ a lanthana was both geographically and systematically isolated. It was the only known Philippine representative of the genus and single representative of the lanthana "group" (DeelemanReinhold \& Platnick 1986; Huber 2011), as it did clearly not fit into any of the other two species groups.

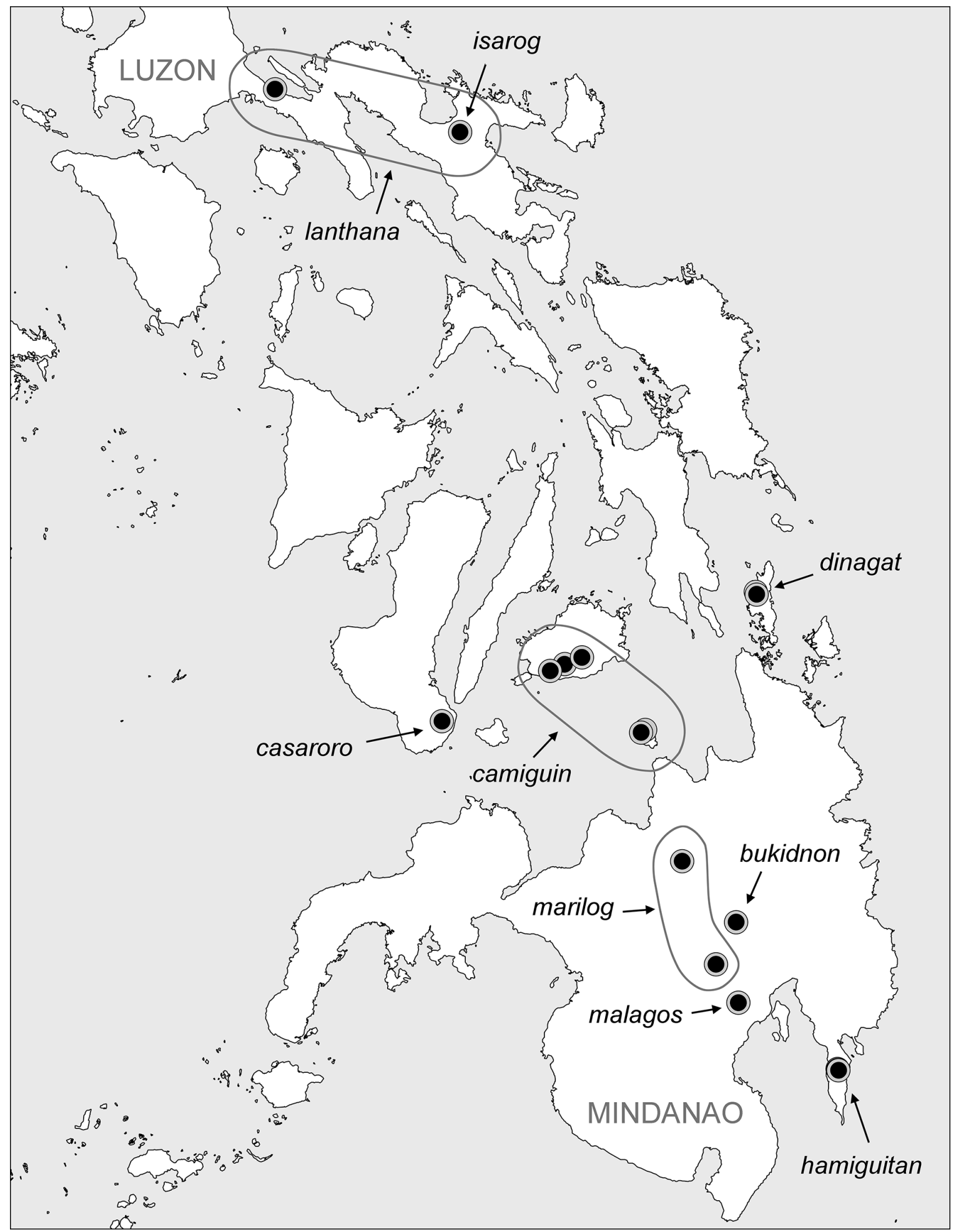

Fig. 16. Known distribution of the Panjange lanthana group. 
With the new species from the Philippines described below, the lanthana group can finally be characterized based on several species, and the emended diagnosis below takes account of these new species.

\section{Diagnosis}

Distinguished from closest known relatives (other species of lanthana group) by absence of processes arising from near male PME (cf. fig. 441 in Huber 2011), by presence of clearly visible AME, and by morphology of male palp (cf. figs 436, 437 in Huber 2011; procursus with two highly distinctive sclerites hinged against proximal part; appendix with simple weakly sclerotized tip). From three species of the lanthana group ( $\mathrm{Pa}$. malagos Huber sp. nov.; Pa. casaroro Huber sp. nov.; Pa. camiguin Huber sp. nov.) also by symmetric palps; from another three species of the lanthana group ( $P a$. isarog Huber sp. nov.; Pa. dinagat Huber sp. nov.; Pa. marilog Huber sp. nov.) also by unmodified male clypeus and by epigynal scape directed toward posterior (fig. 439 in Huber 2011); from Pa. hamiguitan Huber sp. nov. also by much shorter palpal segments and epigynal scape.

\section{New material examined}

PHILIPPINES: Luzon, Camarines Sur Province: $2 \hat{\jmath} \widehat{\partial}, 4$ + $\propto$ in ZFMK (Ar12997) and $1 \hat{\jmath}, 1 \uparrow$ in MSU-IIT, Mt. Isarog, W slope $\left(13.664^{\circ} \mathrm{N}, 123.34-123.35^{\circ} \mathrm{E}\right), \sim 600-900 \mathrm{~m}$ a.s.l., forest, on leaves, 23 Feb. 2014 (B.A. Huber); 6 juvs in pure ethanol in ZFMK (Phi 224), same data.

\section{Natural history}

All specimens were found in a shady ravine, with their domed webs connected to the undersides of green leaves among the vegetation, about $1-2 \mathrm{~m}$ above the ground.

\section{Distribution}

Known from two localities on southern Luzon Island (Fig. 16).

Panjange malagos Huber sp. nov. urn:Isid:zoobank.org:act:00D7154A-7034-4494-AE2D-026298207059

Figs 5, 17-23

\section{Diagnosis}

Easily distinguished from closest known relatives ( $P a$. casaroro Huber sp. nov.; Pa. camiguin Huber sp. nov.) by short male eye stalks (Fig. 17), and by morphology of male palps (Figs 18-21; symmetric modifications of trochanter and femur; asymmetric shapes of procursi); from $\mathrm{Pa}$. casaroro Huber sp. nov. also by simple epigynal scape without pair of semi-transparent lobes (Fig. 22); from Pa. camiguin Huber sp. nov. also by absence of strong transversal sclerite in female internal genitalia (Fig. 23).

\section{Etymology}

The species name is derived from the type locality; noun in apposition.

\section{Type material}

PHILIPPINES: holotype $\widehat{\alpha}$, in ZFMK (Ar 12998), Mindanao, Davao del Sur Province, Malagos Watershed $\left(7.184^{\circ} \mathrm{N}, 125.415^{\circ} \mathrm{E}\right), 390 \mathrm{~m}$ a.s.l., forest along river, on leaves, 14 Feb. 2014 (B.A. Huber, E. Mondejar).

\section{Other material examined}

PHILIPPINES: $1 \hat{\partial}, 2$ + $q$ in ZFMK (Ar 12999) and $1 q$ in MSU-IIT, same data as holotype; $1 \propto$ in pure ethanol, in ZFMK (Phi 259), same data. 


\section{Description}

Male (holotype)

MEAsurements. Total body length 4.6, carapace width 0.9 . Leg 1: $41.3(9.7+0.4+9.8+19.4+2.0)$, tibia 2: 6.0, tibia 3: 3.2, tibia 4: 4.9; tibia $1 \mathrm{~L} / \mathrm{d}: 110$. Distance PME-PME $270 \mu \mathrm{m}$, diameter PME $120 \mu \mathrm{m}$, distance PME-ALE $40 \mu \mathrm{m}$; AME absent.

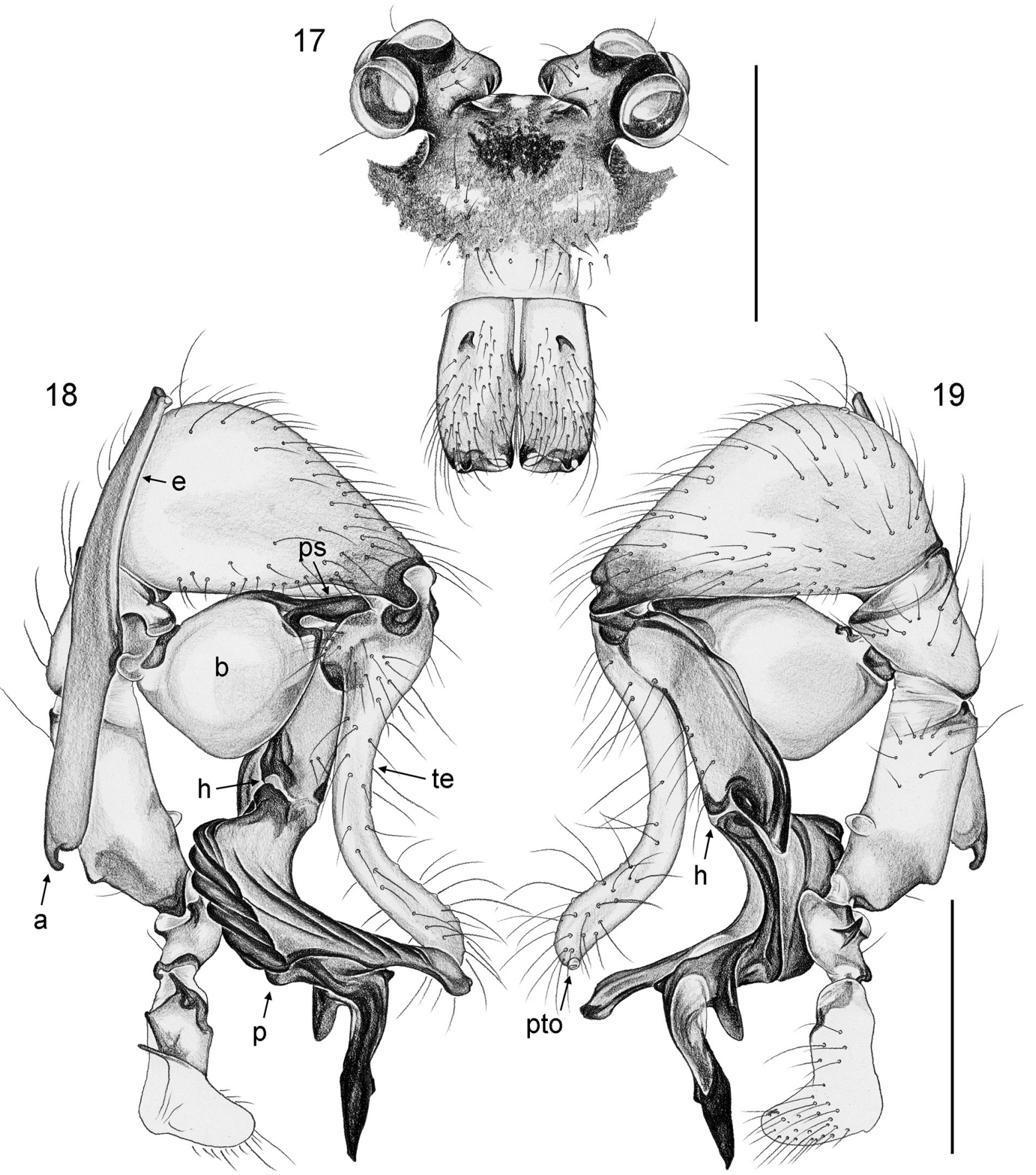

Figs 17-19. Panjange malagos Huber sp. nov. (ZFMK, Ar 12999). 17. Male prosoma and chelicerae, frontal view. 18-19. Left male palp, prolateral and retrolateral views. Abbreviations: $a=$ appendix; $b=$ genital bulb; $\mathrm{e}=$ embolus; $\mathrm{h}=$ hinge; $\mathrm{p}=$ procursus; $\mathrm{ps}=$ proximal bulbal sclerite; $\mathrm{pto}=$ palpal tarsal organ; te $=$ tarsal elongation. Scale bars $=0.5 \mathrm{~mm}$. 
Color. Carapace pale ochre yellow with indistinct posterior median mark, ocular area and clypeus brown, black mark in AME area; sternum whitish; legs ochre-yellow with dark brown patellae and tibiametatarsus joints; abdomen ochre-gray, with black marks dorsally, monochromous ventrally.
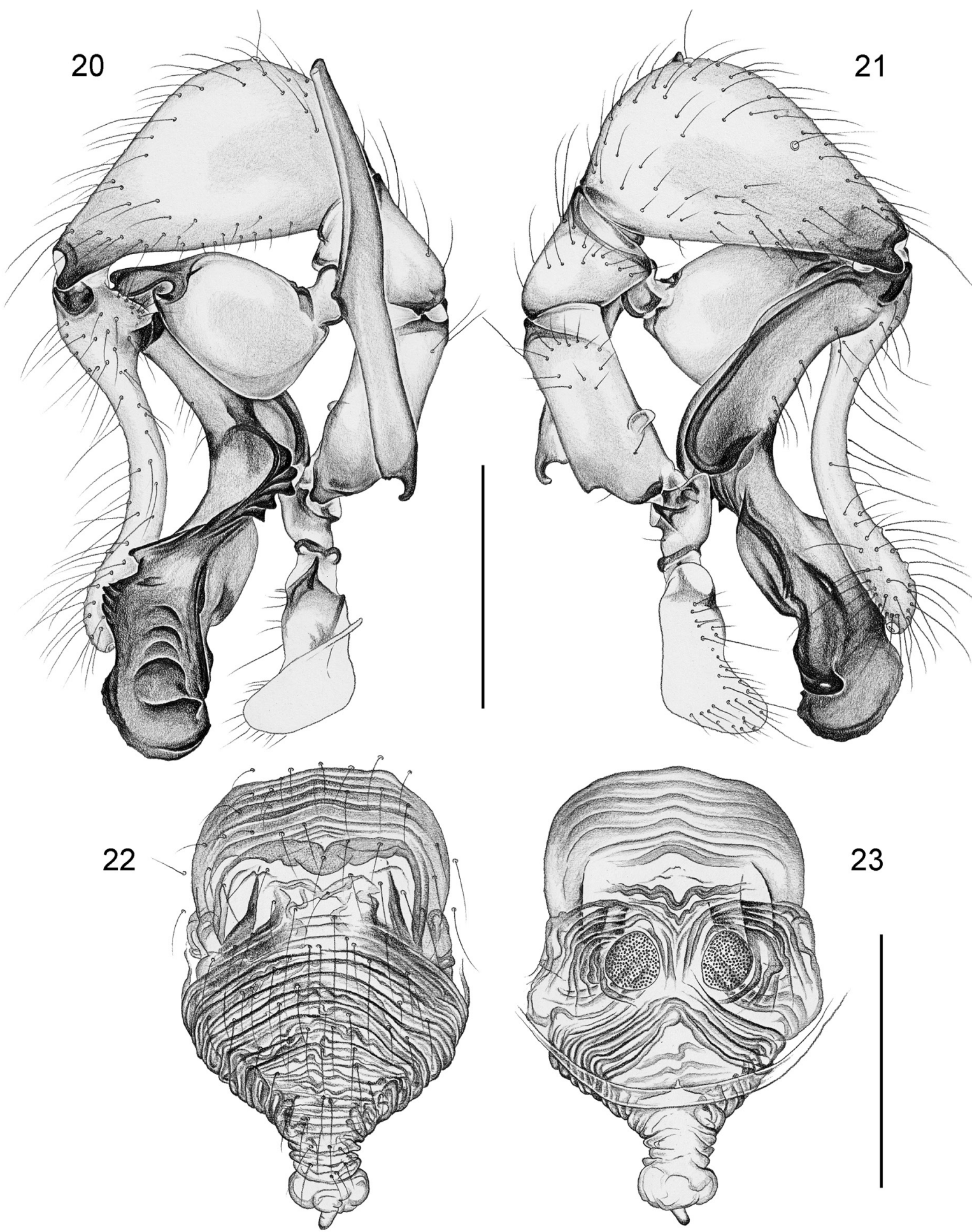

Figs 20-23. Panjange malagos Huber sp. nov. (ZFMK, Ar 12999). 20-21. Right male palp, prolateral and retrolateral views. 22-23. Cleared female genitalia, ventral and dorsal views. Scale bars $=0.5 \mathrm{~mm}$. 
Body. Habitus as in Fig. 5; ocular area raised, each triad on short stalk, medially with pointed process directed toward frontal and ventral (Fig. 17); carapace without median furrow; clypeus unmodified; sternum wider than long $(0.65 / 0.55)$, unmodified.

Chelicerae. As in Fig. 17, with simple pair of weakly sclerotized processes in rather frontal position, without modified hairs; without stridulatory ridges.

PaLPs. As in Figs 18-21; proximal segments symmetric in shape but slightly larger on left side (e.g., length and diameter of right tibia about $95-97 \%$ of left tibia); coxa with strong ventro-distal rim but otherwise unmodified; trochanter with pointed retrolateral apophysis and rounded ventral hump; femur with dorsal hump and weakly sclerotized semitransparent process retrolatero-ventrally; tarsus with long whitish elongation with terminal tarsal organ; procursi of left and right palps strongly different, distal part of procursus clearly hinged in left palp, not hinged in right palp; bulb slightly smaller in right palp, with long processes extending in opposite directions (dorsal embolus; ventral appendix) almost symmetric (slightly longer in left palp).

Legs. Without spines and curved hairs; few vertical hairs; retrolateral trichobothrium on tibia 1 at $3 \%$; prolateral trichobothrium absent on tibia 1, present on other tibiae; tarsus 1 with $>20$ pseudosegments, only distally fairly distinct.

Male (variation)

Not seen. Tibia 1 missing in other male.

\section{Female}

In general similar to male but eye triads on low humps and closer together (distance PME-PME $210 \mu \mathrm{m}$ ). Tibia 1 in 3 females: 6.9, 7.0, 7.9. Epigynum large elongate plate, anterior part weakly sclerotized, with symmetric or at most slightly asymmetric internal structures visible through cuticle; posterior part orange, with extensible scape with distinct transversal folds and small median process ("knob") at tip (Fig. 22); internal genitalia as in Fig. 23.

\section{Natural history}

The spiders were found in very low abundance on the undersides of leaves about $50-200 \mathrm{~cm}$ above the ground in a disturbed part of the forest.

\section{Distribution}

Known from type locality on Mindanao Island only (Fig. 16).

Panjange casaroro Huber sp. nov. urn:1sid:zoobank.org:act:D6FF36FF-D69F-4F92-919F-82F423701E71

Figs 6-7, 24-34

\section{Diagnosis}

Easily distinguished from closest known relatives (Pa. malagos Huber sp. nov.; Pa. camiguin Huber sp. nov.) by morphology of male palps (Figs 24-27; symmetric modifications of trochanter and femur; asymmetric shapes of procursi), and by pair of semi-transparent lobes on epigynal scape (Figs 29, 33). From most congeners (except $P a$. camiguin Huber sp. nov.) also by very long eye stalks and contiguous tips of male ocular processes (Fig. 28); from Pa. camiguin Huber sp. nov. also by proximally unmodified male chelicerae (densely covered with small scales in Pa. camiguin Huber sp. nov.; cf. Fig. 47) and by small process between eye stalks (Fig. 28). 


\section{Etymology}

The species name is derived from the type locality; noun in apposition.

\section{Type material}

PHILIPPINES: holotype ${ }^{\lambda}$, in ZFMK (Ar 13000), Negros Island, Negros Oriental Province, Casaroro Falls $\left(9.281^{\circ} \mathrm{N}, 123.208^{\circ} \mathrm{E}\right), 550 \mathrm{~m}$ a.s.l., forest along river below waterfall, on leaves, 10 Mar. 2014 (B.A. Huber).

\section{Other material examined}

PHILIPPINES: $1 \hat{\jmath}, 3$ 우 in ZFMK (Ar 13001) and $1 \hat{\partial}, 1 q$ in MSU-IIT, same data as holotype; $1 \uparrow$, 1 juv. in pure ethanol, in ZFMK (Phi 187), same data.
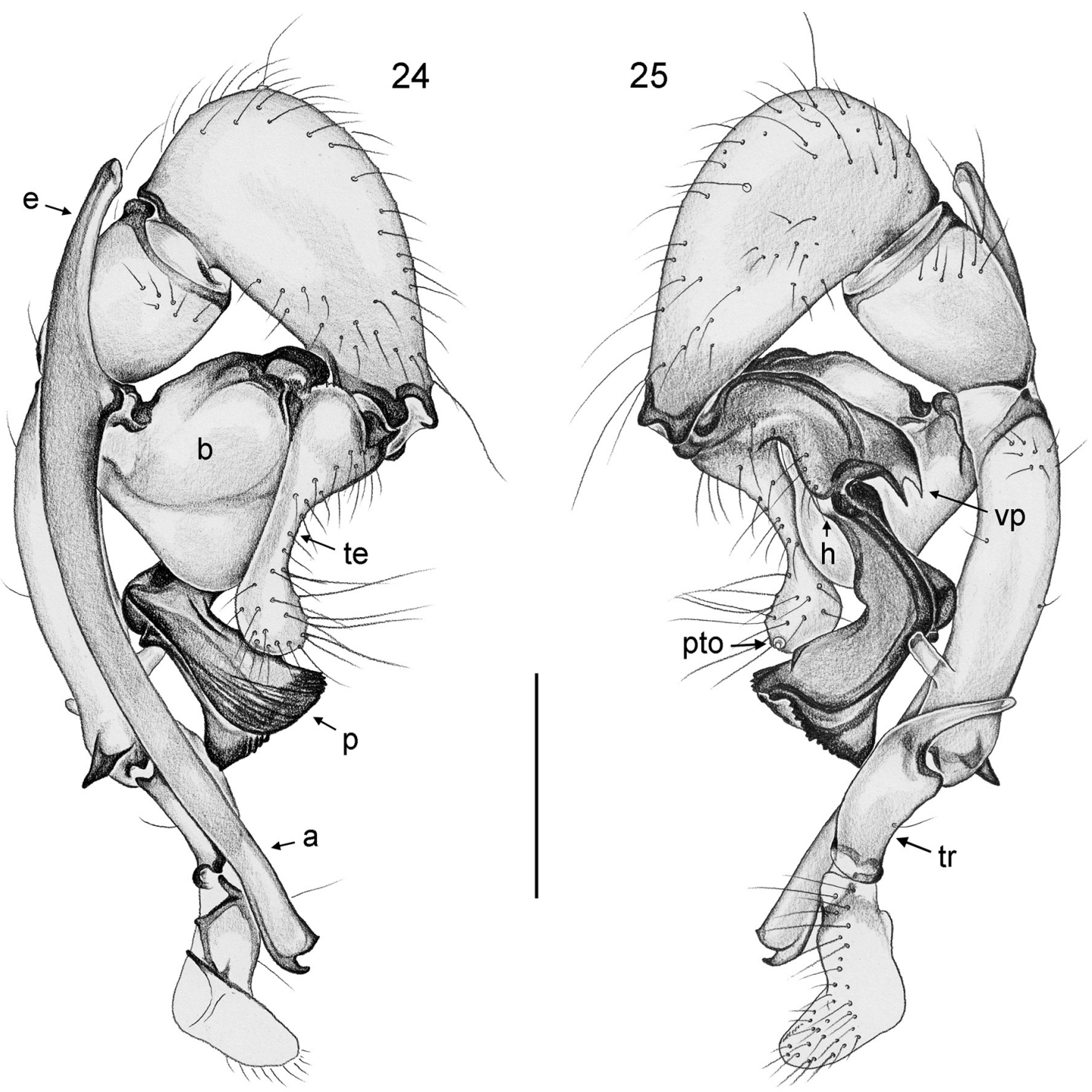

Figs 24-25. Panjange casaroro Huber sp. nov. (ZFMK, Ar 13001), left male palp, prolateral and retrolateral views. Abbreviations: $\mathrm{a}=$ appendix; $\mathrm{b}=$ genital bulb; $\mathrm{e}=$ embolus; $\mathrm{h}=$ hinge; $\mathrm{p}=$ procursus; pto $=$ palpal tarsal organ; te $=$ tarsal elongation; $\operatorname{tr}=$ trochanter; $\mathrm{vp}=$ ventral process. Scale bar $=0.5 \mathrm{~mm}$. 


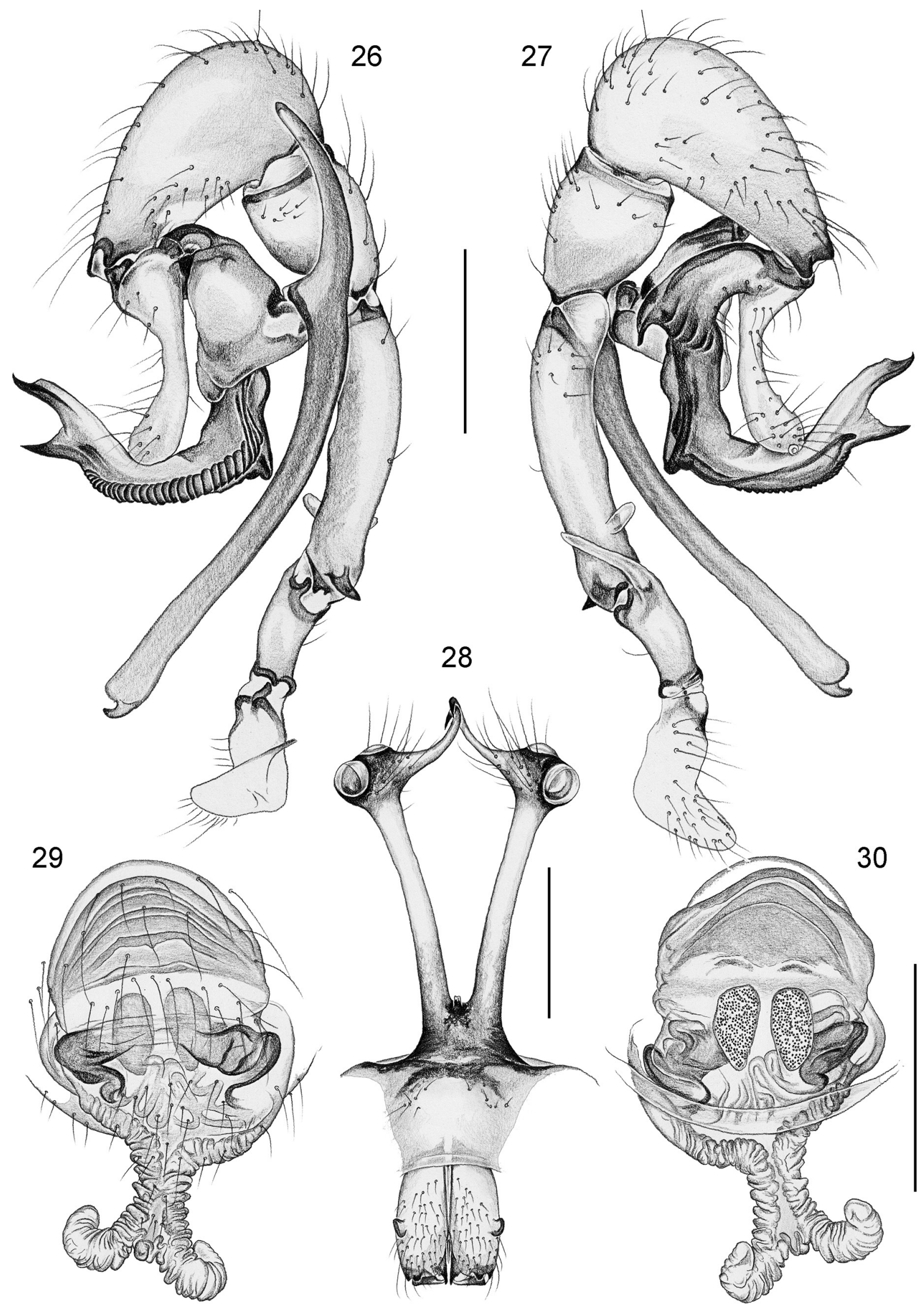

Figs 26-30. Panjange casaroro Huber sp. nov. (ZFMK, Ar 13001). 26-27. Right male palp, prolateral and retrolateral views. 28. Male prosoma and chelicerae, frontal view. 29-30. Cleared female genitalia, ventral and dorsal views. Scale bars $=0.5 \mathrm{~mm}$. 
HUBER B.A. \& NUÑEZA O.M., Evolution of Panjange spiders

\section{Description}

Male (holotype)

MeAsurements. Total body length 4.8, carapace width 1.0. Leg 1: $39.2(9.2+0.5+9.4+18.9+1.2)$, tibia 2: 5.6, tibia 3: 3.2, tibia 4: 4.9; tibia $1 \mathrm{~L} / \mathrm{d}$ : 106. Distance PME-PME $420 \mu \mathrm{m}$, diameter PME $105 \mu \mathrm{m}$, distance PME-ALE $\sim 30 \mu \mathrm{m}$; AME absent.
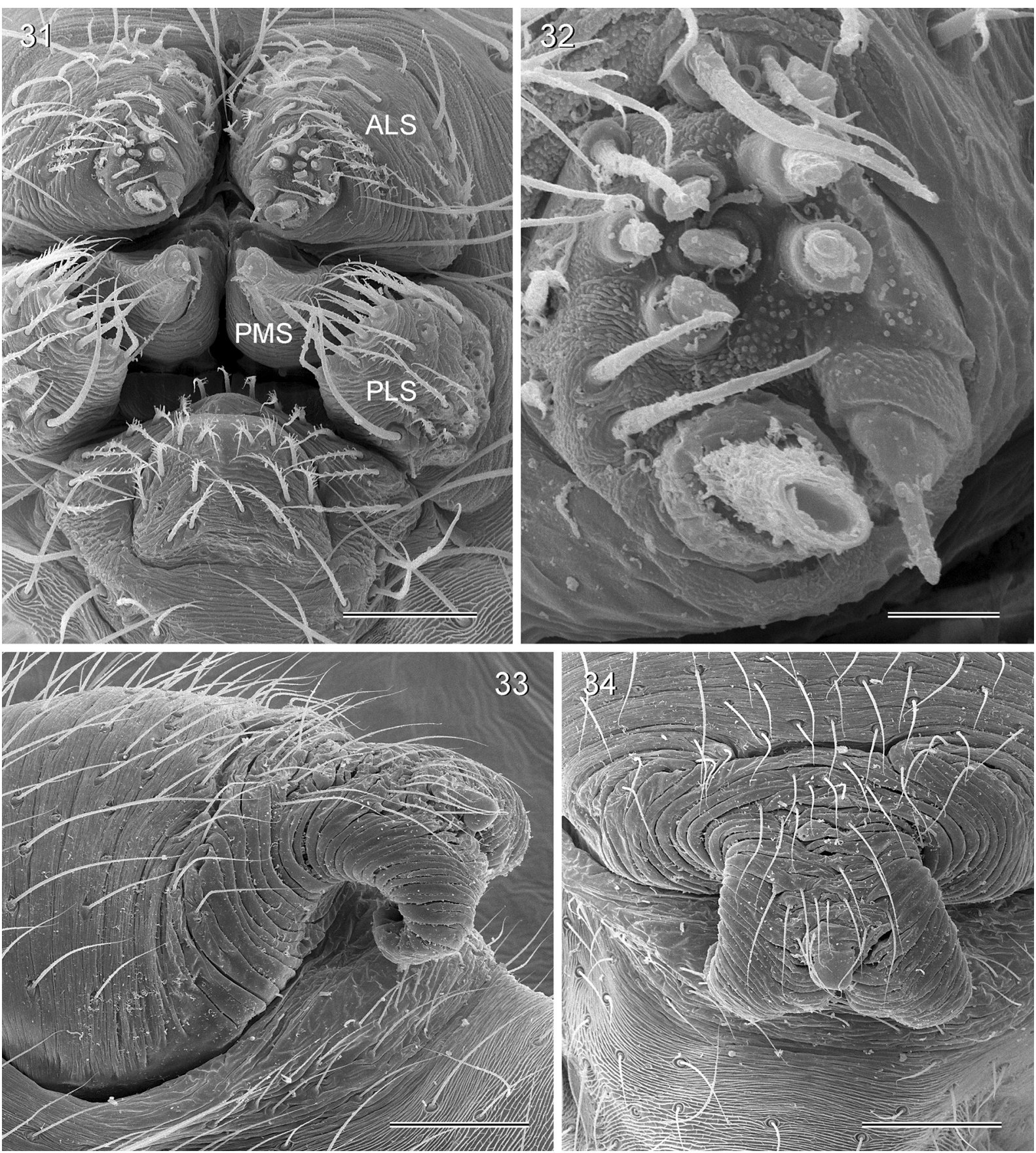

Figs 31-34. Panjange casaroro Huber sp. nov., SEM micrographs (ZFMK, Ar 13001). 31. Female spinnerets. 32. Female ALS. 33-34. Epigynum and scape. 33. Lateral (slightly posterior) view. 34. Ventral view. Abbreviations: ALS, anterior lateral spinneret; PLS = posterior lateral spinneret; PMS = posterior median spinneret. Scale bars: $31=60 \mu \mathrm{m} ; 32=10 \mu \mathrm{m} ; 33-34=100 \mu \mathrm{m}$. 
Color. Carapace and clypeus pale ochre to whitish, only base of eye stalks dark; sternum whitish; legs ochre-yellow with dark brown patellae and tibia-metatarsus joints; abdomen pale gray, with black marks dorsally, monochromous ventrally.

BoDy. Habitus as in Figs 6-7; ocular area raised, triads on long stalks with further distal processes whose contiguous tips seem to form a functional unit (Fig. 28); with small process between eye stalks; carapace without median furrow; clypeus unmodified; sternum wider than long $(0.65 / 0.55)$, unmodified.

Chelicerae. As in Fig. 28, with pair of simple, weakly sclerotized lateral processes, without modified hairs; without stridulatory ridges.

PALPS. As in Figs 24-27; proximal segments symmetric in shape but slightly larger on left side (e.g., length and diameter of right tibia about $90-95 \%$ of left tibia); coxa with strong ventro-distal rim but otherwise unmodified; trochanter with long weakly sclerotized retrolateral process directed toward dorsal; femur with weakly sclerotized finger-shaped process retrolatero-ventrally and more heavily sclerotized apophysis prolatero-dorsally; tibia with retrolateral trichobothrium in rather proximal position; tarsus with long whitish elongation, distally more strongly widened (club-shaped) in left palp; procursi of left and right palps strongly different, in each case with ventral process arising from proximal part (simple in right palp; bifid in left palp); distal part of procursus clearly hinged in left palp, not hinged in right palp; bulb much smaller in right palp, long processes extending in opposite directions (dorsal embolus; ventral appendix) almost symmetric (slightly longer in left palp).

LEgs. Without spines and curved hairs; few vertical hairs; retrolateral trichobothrium on tibia 1 at 3\%; prolateral trichobothrium absent on tibia 1, present on other tibiae; tarsus 1 with $>20$ pseudosegments, only distally fairly distinct.

Male (variation)

Tibia 1 in other male: 9.5 (missing in third male).

\section{Female}

In general similar to male but eye triads on low humps and much closer together (distance PME-PME $265 \mu \mathrm{m}$ ); with dark mark in place of AME. Tibia 1 in 4 females: 6.7, 7.0, 7.1, 7.4. Epigynum mostly weakly sclerotized, with apparently slightly asymmetric internal structures visible through cuticle; distinctive scape with small median process at tip and two long extensible projections curved toward dorsal (Figs 29, 33, 34); internal genitalia as in Fig. 30.

\section{Natural history}

The spiders were found on the undersides of large leaves about $50-100 \mathrm{~cm}$ above the ground.

\section{Distribution}

Known from type locality on Negros Island only (Fig. 16).

Panjange camiguin Huber sp. nov. urn:1sid:zoobank.org:act:A8245A4A-D792-4023-8E50-0922A9C29FD6

Figs 8-10, 35-63

\section{Diagnosis}

Easily distinguished from closest known relatives (Pa. malagos Huber sp. nov.; Pa. casaroro Huber sp. nov.) by morphology of male palps (Figs 38-39; symmetric modifications of trochanter and femur; asymmetric shapes of procursi; Figs 41-44), by proximally modified male chelicerae (densely covered 
with small scales; Fig. 47), and by strong internal sclerite in female genitalia (Fig. 37). From most congeners (except $\mathrm{Pa}$. casaroro Huber sp. nov.) also by contiguous tips of male ocular processes (Figs 35, 45, 48-49); from $\mathrm{Pa}$. casaroro Huber sp. nov. also by absence of process between eye stalks (Fig. 35 ), and by simple epigynal scape (Fig. 36; not with two distal lobes).

\section{Etymology}

The species name is derived from the type locality; noun in apposition.

\section{Type material}

PHILIPPINES: holotype $\widehat{\partial}$, in ZFMK (Ar 13002), Camiguin Island, Katibawasan Falls $\left(9.215^{\circ} \mathrm{N}\right.$, $\left.124.720^{\circ} \mathrm{E}\right), 300 \mathrm{~m}$ a.s.1., on leaves, 19 Feb. 2014 (B.A. Huber, P.N. Banaag).

\section{Other material examined}

PHILIPPINES: Camiguin Island: $7 \hat{\jmath}, 17 q q, 1$ juv. in ZFMK (Ar 13003, 13004) and $1 \hat{\sigma}, 1 q$ in MSU-IIT, same data as holotype; 2 우, 2 juvs in pure ethanol, in ZFMK (Phi 235), same data; $2 \hat{\jmath} \widehat{0}$, 2 우, 2 juvs in ZFMK (Ar 13005) and 1 $\lambda, 1$ in MSU-IIT, all poorly preserved, same locality, 5-6

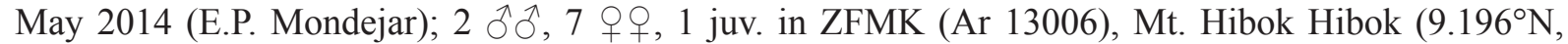
$124.692^{\circ} \mathrm{E}$ ), $600 \mathrm{~m}$ a.s.l., on leaves, 18 Feb. 2014 (B.A. Huber, P.N. Banaag); 2 o 9,2 juvs in pure

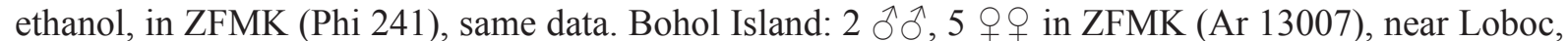
above Loboc River $\left(\sim 9.655^{\circ} \mathrm{N}, 124.015^{\circ} \mathrm{E}\right), \sim 250 \mathrm{~m}$ a.s.l., forest near caves, 5 Mar. 2014 (B.A. Huber);

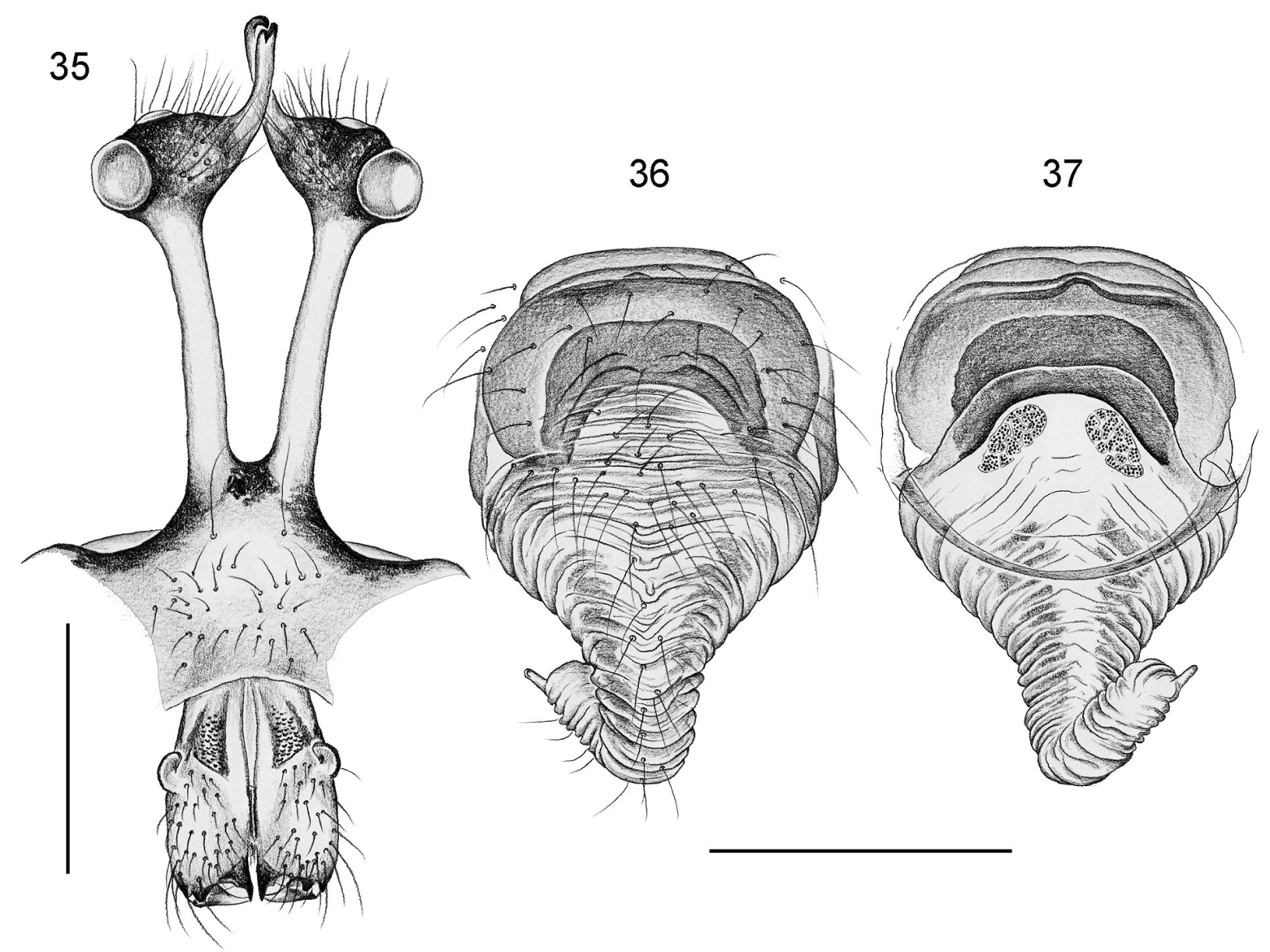

Figs 35-37. Panjange camiguin Huber sp. nov. (ZFMK, Ar 13003, 13004). 35. Male prosoma and chelicerae, frontal view. 36-37. Cleared female genitalia, ventral and dorsal views. Scale bars $=0.5 \mathrm{~mm}$. 


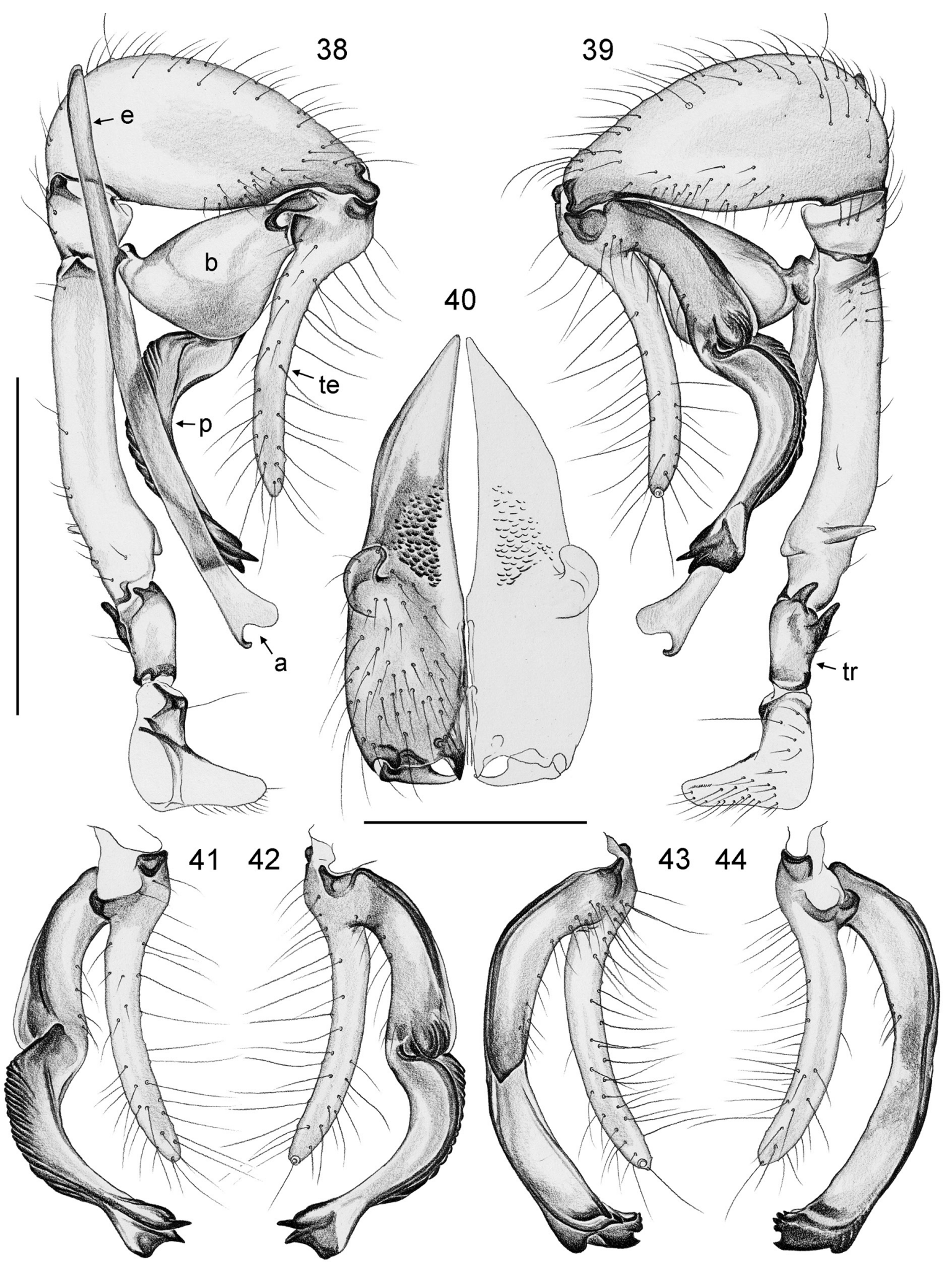

Figs 38-44. Panjange camiguin Huber sp. nov. (ZFMK, Ar 13003). 38-39. Left male palp, prolateral and retrolateral views. 40. Male chelicerae, frontal view. 41-42. Left male tarsus and procursus, prolateral and retrolateral views. 43-44. Right male tarsus and procursus, retrolateral and prolateral views. Abbreviations: $\mathrm{a}=$ appendix; $\mathrm{b}=$ genital bulb; $\mathrm{e}=$ embolus; $\mathrm{p}=$ procursus; te $=$ tarsal elongation; $\operatorname{tr}=$ trochanter. Scale bars: $38-39,41-44=1 \mathrm{~mm} ; 40=0.3 \mathrm{~mm}$. 


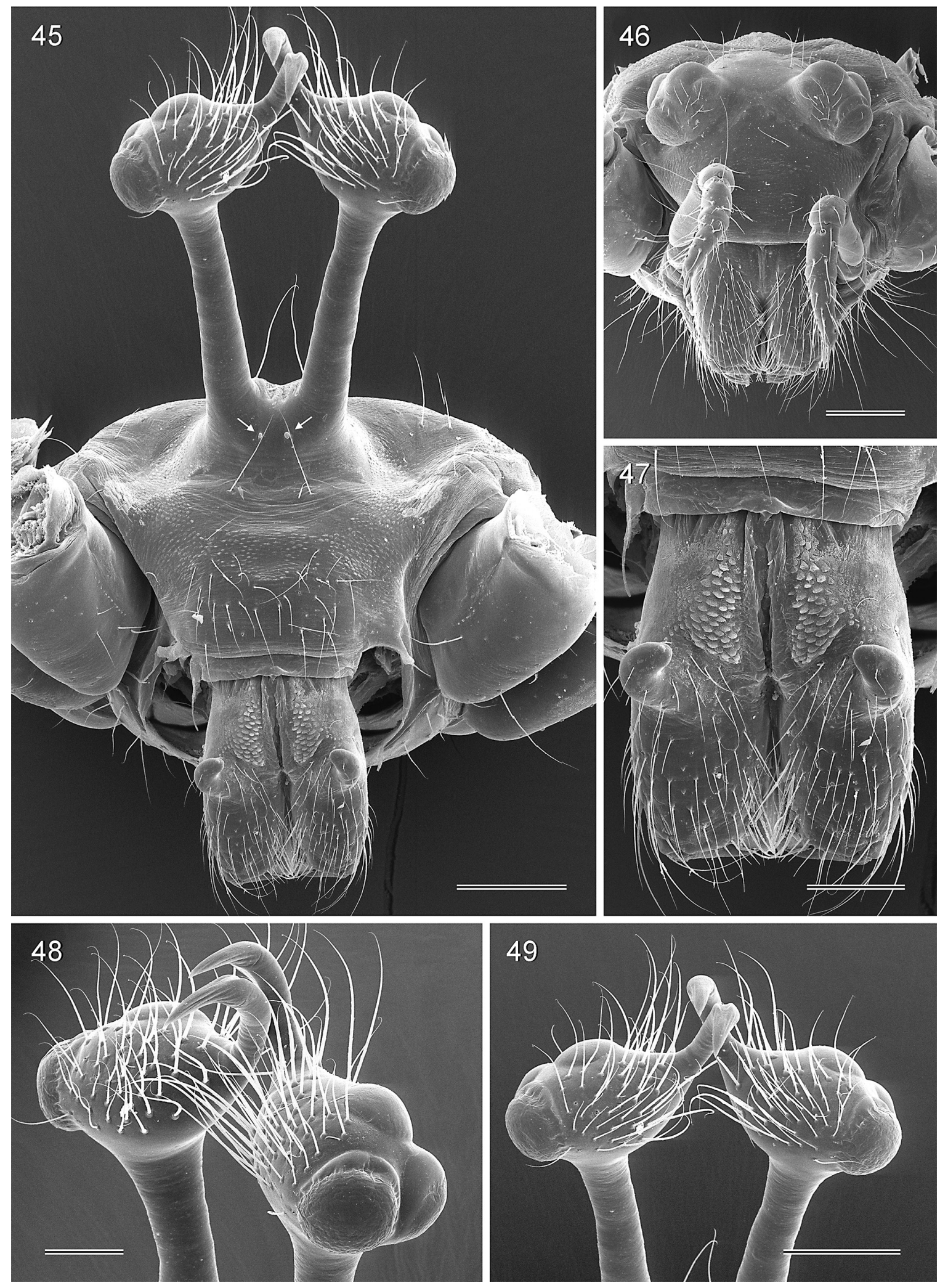

Figs 45-49. Panjange camiguin Huber sp. nov., SEM micrographs (ZFMK, Ar 13003, 13004). 4546. Male and female prosomata, frontal views (arrows point at tiny AME remnants). 47. Male chelicerae. 48-49. Male eye triads and ocular processes, oblique frontal and frontal views. Scale bars: $45-46,49=$ $200 \mu \mathrm{m} ; 47-48=100 \mu \mathrm{m}$. 

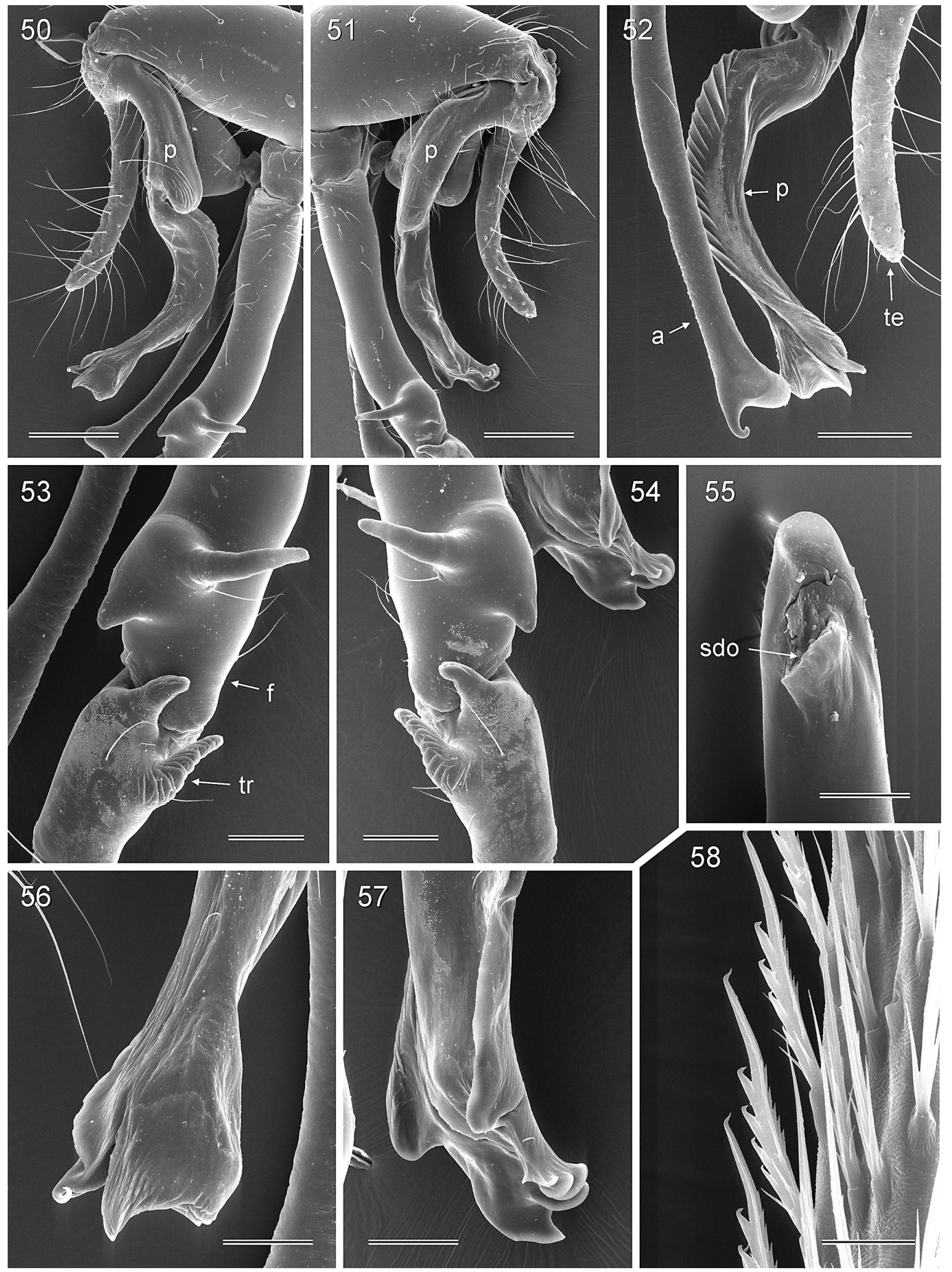

Figs 50-58. Panjange camiguin Huber sp. nov., SEM micrographs (ZFMK, Ar 13003, 13004). 5051. Left and right male palps, retrolateral views. 52. Left procursus and appendix, prolateral view. 5354. Left and right male palpal trochanters and femora proximally, retrolateral views. 55. Tip of embolus. 56-57. Left and right procursus tips, retrolateral views. 58. Comb-hairs on female tarsus 4 . Abbreviations: $\mathrm{a}=$ appendix; $\mathrm{f}=$ femur; $\mathrm{p}=$ procursus; $\mathrm{sdo}=$ sperm duct opening; te $=$ tarsal elongation; $\mathrm{tr}=$ trochanter. Scale bars: $50-51=300 \mu \mathrm{m} ; 52=200 \mu \mathrm{m} ; 53-54=100 \mu \mathrm{m} ; 55=30 \mu \mathrm{m} ; 56-57=80 \mu \mathrm{m} ; 58=20 \mu \mathrm{m}$. 
1 +, 3 juvs in pure ethanol, in ZFMK (Phi 199), same data; 1 q with 8 hymenopteran parasites and 2 juveniles emerged from same egg sac, in pure ethanol in ZFMK (Phi 291), same data (Fig. 8); 1 万, 4 우우 1 juv. in ZFMK (Ar 13008), Rajah Sikatuna (Magsaysay Park) $\left(9.705^{\circ} \mathrm{N}, 124.123^{\circ} \mathrm{E}\right), 430 \mathrm{~m}$ a.s.l., forest, on leaves, 6 Mar. 2014 (B.A. Huber); 4 juvs in pure ethanol in ZFMK (Phi 194), same data;

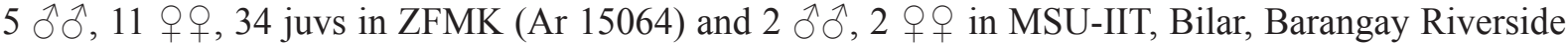
$\left(\sim 9.705^{\circ} \mathrm{N}, 12.125^{\circ} \mathrm{E}\right), 15$ Jun. 2015 (M.R.B. Dacar).
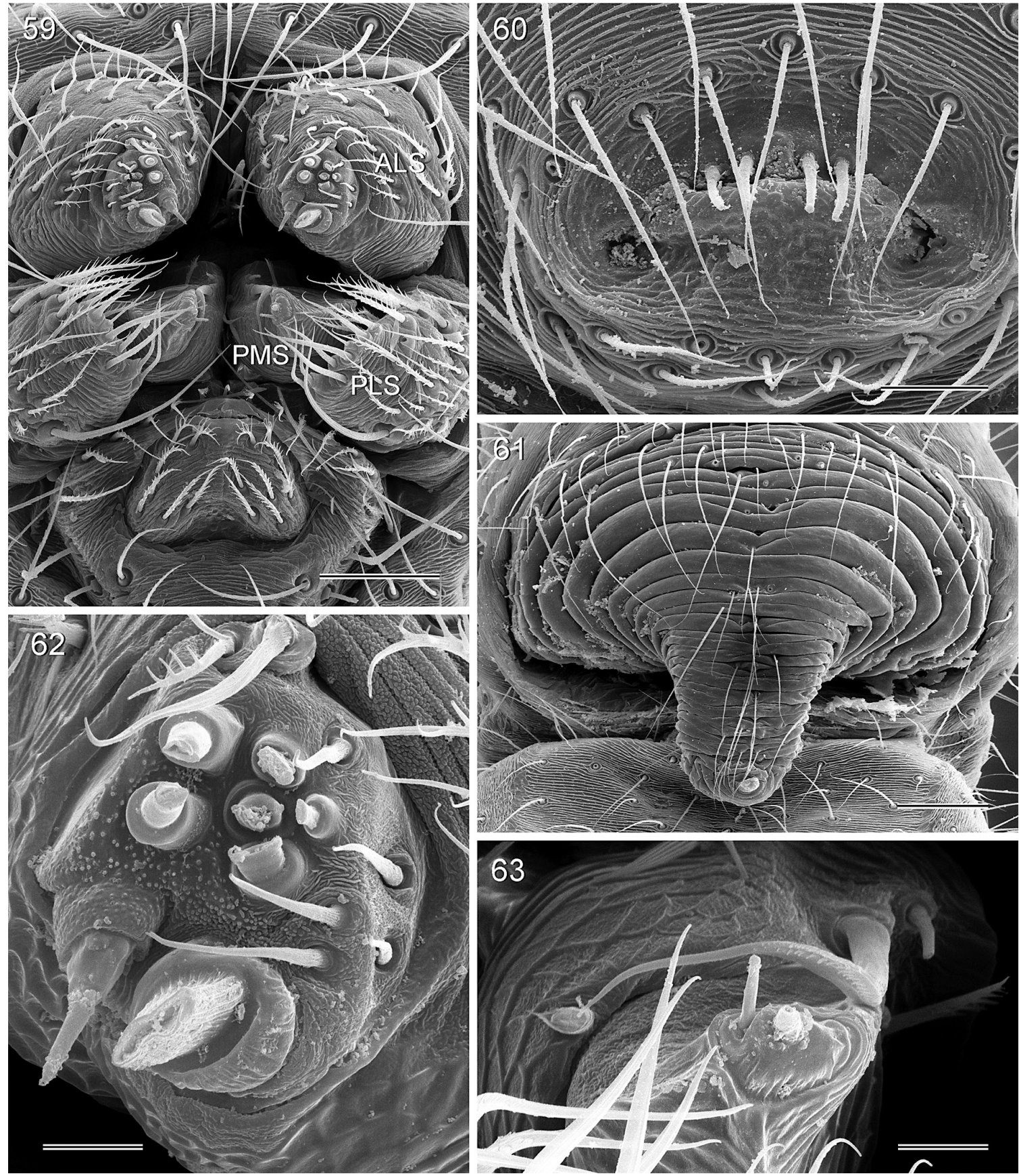

Figs 59-63. Panjange camiguin Huber sp. nov., SEM micrographs (ZFMK, Ar 13003, 13004). 59. Female spinnerets. 60. Male gonopore. 61. Epigynum and scape, ventral view. 62. Female ALS. 63. Female PMS. Abbreviations: ALS = anterior lateral spinneret; PLS = posterior lateral spinneret; PMS $=$ posterior median spinneret. Scale bars: $59=60 \mu \mathrm{m} ; 60=30 \mu \mathrm{m} ; 61=100 \mu \mathrm{m} ; 62-63=10 \mu \mathrm{m}$. 


\section{Assigned tentatively}

PHILIPPINES, Bohol Island: $2 \widehat{\partial} \widehat{\partial}, 4$ juvs in ZFMK (Ar 15065) and 1 $\widehat{\partial}$ in MSU-IIT, Garcia Hernandez,

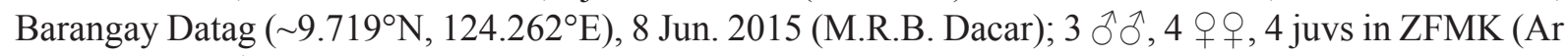
15066) and 1 ग, 1 in MSU-IIT, Valencia, Barangay Marawis $\left(9.723^{\circ} \mathrm{N}, 124.202^{\circ} \mathrm{E}\right), 10-11 \mathrm{Jun} .2015$ (M.B.R. Dacar); $2 \lambda \lambda, 8$ 우, 5 juvs in ZFMK (Ar 15067) and $1 \hat{\jmath}, 1$ 우 in MSU-IIT, Sierra Bullones, Barangay Nan-od ( $\left.\sim 9.748^{\circ} \mathrm{N}, 124.264^{\circ} \mathrm{E}\right), 4-5$ Jun. 2015 (M.R.B. Dacar).

\section{Description}

\section{Male (holotype)}

Measurements. Total body length 5.0, carapace width 1.0. Leg 1: $43.2(9.8+0.5+9.9+21.1+1.9)$, tibia 2: 6.1, tibia 3: 3.1, tibia 4: 5.0; tibia $1 \mathrm{~L} / \mathrm{d}: 103$. Distance PME-PME $355 \mu \mathrm{m}$, diameter PME $125 \mu \mathrm{m}$, distance PME-ALE $\sim 35 \mu \mathrm{m}$; with tiny AME lenses barely visible in dissecting microscope, diameter $\sim 10 \mu \mathrm{m}$ (Fig. 45).

Color. Carapace pale ochre with darker triangular mark posteriorly, pair of dark marks lateral of base of eye stalks, and median mark in AME area; clypeus without pattern; sternum whitish; legs ochre-yellow with dark brown patellae and tibia-metatarsus joints; abdomen pale gray, with black marks dorsally, monochromous ventrally.

Body. Habitus as in Figs 9-10; ocular area raised, triads on long additional stalks with further distal processes whose contiguous tips seem to form a functional unit (Figs 35, 45, 48-49); without process between eye stalks; carapace without median furrow; clypeus unmodified; sternum wider than long $(0.70 / 0.50)$, unmodified.

Chelicerae. As in Fig. 47, with pair of curved, weakly sclerotized lateral processes, proximally densely covered with small scales; without modified hairs; without stridulatory ridges.

PaLPs. As in Figs 38-39, 50-51; proximal segments symmetric in shape and apparently also in size (Figs 53-54); coxa with strong ventro-distal rim but otherwise unmodified; trochanter with distinctive pair of apophyses (retrolateral and dorsal; Figs 53, 54); femur with weakly sclerotized retrolateral process directed toward dorsal and short ventral process directed toward proximal (Figs 53, 54); patella very small; tibia large; tarsus with long whitish elongation; procursi of left and right palps slightly but clearly different, distal part of procursus hinged in left palp, not hinged in right palp (Figs 41-44); bulb symmetric in shape, with long processes extending in opposite directions (dorsal embolus; ventral appendix), apparently slightly longer in left palp.

LEGS. Without spines and curved hairs; few vertical hairs; retrolateral trichobothrium on tibia 1 at 3\%; prolateral trichobothrium absent on tibia 1, present on other tibiae; tarsus 1 with $>20$ pseudosegments, only distally fairly distinct.

Male (variation)

Tibia 1 in 11 other males: 8.6-10.1 (mean 9.5). Males from the three eastern sites on Bohol Island (Datag, Marawis, Nan-od) differ slightly but consistently from other specimens in the tip of the right procursus that has a distinct retrolateral process. Specimens from these localities are therefore assigned tentatively.

\section{Female}

In general similar to male but eye triads on low humps and much closer together (distance PME-PME $260 \mu \mathrm{m}$ ), without AME remnants (Fig. 46); posterior mark on carapace smaller, often medially divided; dark abdomen spots in some specimens very indistinct or even absent. Tibia 1 in 32 females: 6.4-8.2 (mean 
7.1). Epigynum apparently symmetric, mostly weakly sclerotized, with strong internal transversal sclerite visible through cuticle; extensible scape with strong transversal folds, laterally light brown to orange, with small median process at tip (Figs 36,61); internal genitalia as in Fig. 37, also apparently symmetric.

\section{Natural history}

The spiders were found on the undersides of large leaves to which they attach fairly dense but barely visible sheets of silk. One female was collected on 5 Mar. 2014 with a parasitized egg sac from which all eggs hatched on 12 Mar. 2014 (two spiders and eight wasps).

\section{Distribution}

Known from Camiguin and Bohol Islands (Fig. 16).

Panjange hamiguitan Huber sp. nov. urn:1sid:zoobank.org:act:C44C7291-5943-45C1-AAC1-F6B684836BBD

Figs 64-68

\section{Diagnosis}

Easily distinguished from known congeners by extremely elongated male palpal elements and female epigynal scape (Figs 64-65, 67).

\section{Etymology}

The species name is derived from the type locality; noun in apposition.

\section{Type material}

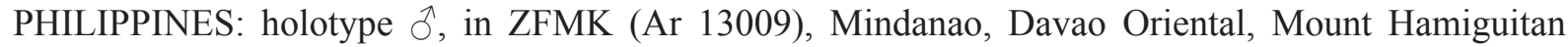
Wildlife Sanctuary (access Governor Generoso), "site 1" $\left(9.6463^{\circ} \mathrm{N}, 126.1442^{\circ} \mathrm{E}\right), 250 \mathrm{~m}$ a.s.1., 12 Feb. 2015 (M.A. Responte).

\section{Other material examined}

PHILIPPINES, Mindanao, Davao Oriental: 1 , 2 juvs in ZFMK (Ar 13010) and 1 in MSU-IIT, same data as holotype; 1 , , 1 juv. in ZFMK (Ar 13011), Mount Hamiguitan Wildlife Sanctuary (access Governor Generoso), "site 2" $\left(9.6497^{\circ} \mathrm{N}, 126.1487^{\circ} \mathrm{E}\right), 360 \mathrm{~m}$ a.s.l., 13 Feb. 2015 (M.A. Responte); 1 q, 1 juv. in ZFMK (Ar 13012), Mount Hamiguitan Wildlife Sanctuary (access Governor Generoso), “site 3" $\left(9.6569^{\circ} \mathrm{N}, 126.1559^{\circ} \mathrm{E}\right), 580 \mathrm{~m}$ a.s.1., 13 Feb. 2015 (M.A. Responte).

\section{Description}

Male (holotype)

MEASUREMENTS. Total body length 5.1, carapace width 0.9. Leg 1: 33.3 $(7.9+0.4+7.8+15.7+\sim 1.5)$, tibia 2: 4.9, tibia 3: 2.8, tibia 4: 4.3; tibia $1 \mathrm{~L} / \mathrm{d}$ : 99. Distance PME-PME $195 \mu \mathrm{m}$, diameter PME $95 \mu \mathrm{m}$, distance PME-ALE $\sim 60 \mu \mathrm{m}$; AME absent.

COLOR. Carapace pale ochre-yellow with pair of light brown marks, ocular area dark brown, with black marks in place of AME, clypeus pale ochre to whitish; sternum whitish; legs pale ochre-yellow with dark brown patellae and tibia-metatarsus joints; abdomen pale gray, with many black marks dorsally and laterally; ventrally with pair of small dark marks near book-lung covers.

Body. Habitus similar to Pa. casaroro Huber sp. nov. and Pa. camiguin Huber sp. nov. (cf. Figs 6, 9); ocular area raised, triads on additional stalks with further weakly sclerotized distal processes directed toward each other (Fig. 66); carapace without median furrow; clypeus unmodified; sternum wider than long (0.56/0.46), unmodified. 
Chelicerae. As in Fig. 66, with pair of simple, weakly sclerotized frontal processes slightly directed upwards, without modified hairs; without stridulatory ridges.

PALPS. As in Figs 64-65; all elements symmetrical; all elements distal of trochanter extremely elongated; coxa with distinct ventral apophysis; trochanter with two weakly sclerotized retrolateral processes; femur with weakly sclerotized bifid retrolateral process proximally; tarsus with extremely slender elongation,

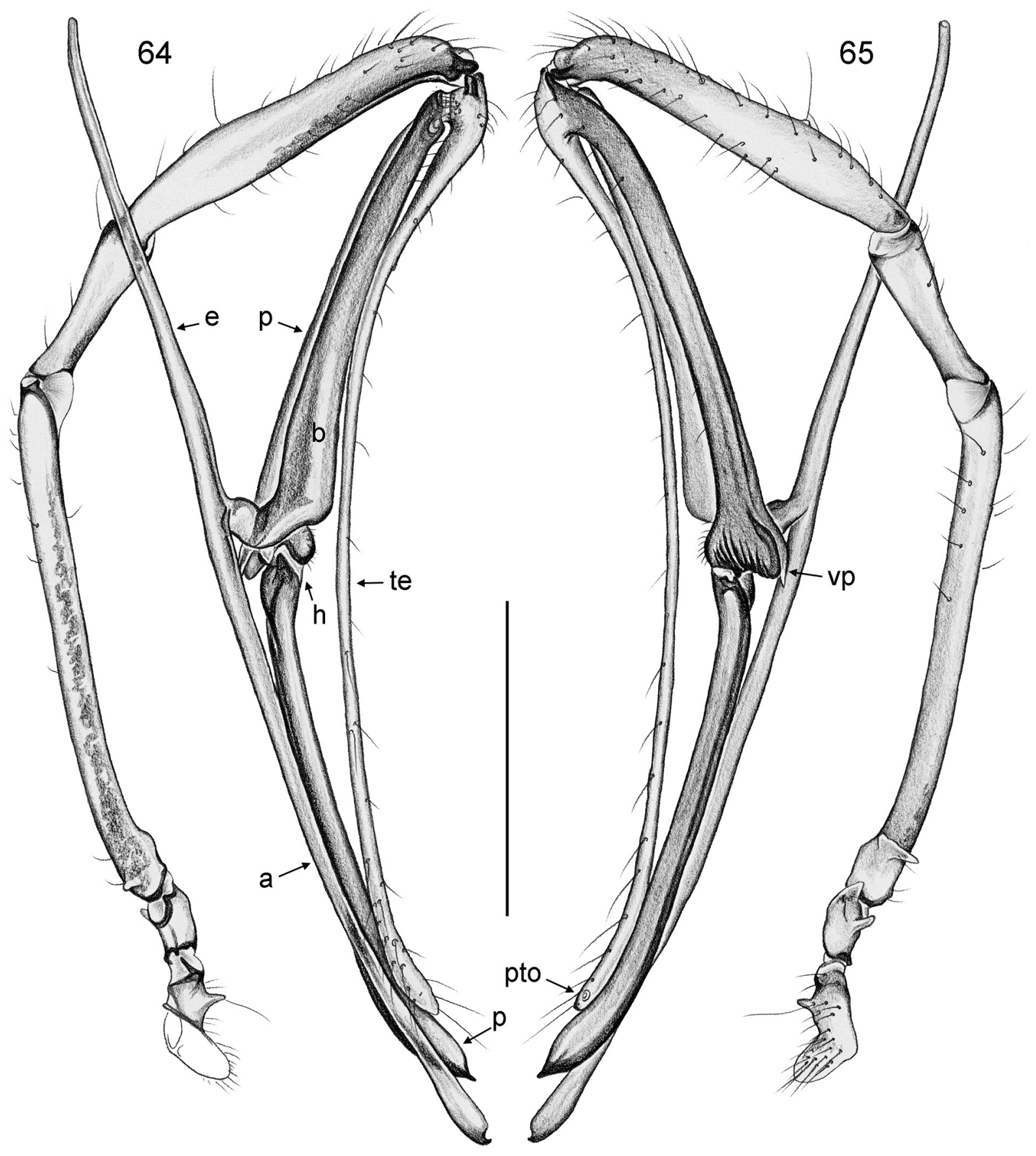

Figs 64-65. Panjange hamiguitan Huber sp. nov. (ZFMK, Ar 13009), left male palp, prolateral and retrolateral views. Abbreviations: $\mathrm{a}=$ appendix; $\mathrm{b}=$ genital bulb; $\mathrm{e}=$ embolus; $\mathrm{h}=$ hinge; $\mathrm{p}=$ procursus; pto $=$ palpal tarsal organ; te $=$ tarsal elongation; $\mathrm{vp}=$ ventral process. Scale bar $=1 \mathrm{~mm}$. 
with tarsal organ near tip; procursus consisting of two hinged parts; proximal part distally widened, with small pointed ventral process; distal part very simple; bulb very thin and long, with long processes extending in opposite directions (dorsal embolus; ventral appendix).

LEGS. Without spines and curved hairs; few vertical hairs; retrolateral trichobothrium on tibia 1 at 3\%; prolateral trichobothrium absent on tibia 1, present on other tibiae.

\section{Female}

In general similar to male but eye triads on low humps, ocular area with narrow transversal dark mark including black marks in place of AME. Tibia 1: 6.8 (missing in other females). Epigynum pale, weakly sclerotized, with very long strongly folded and extensible scape (Fig. 67); internal genitalia as in Fig. 68.

\section{Distribution}

Known from type locality on Mindanao only (Fig. 16).

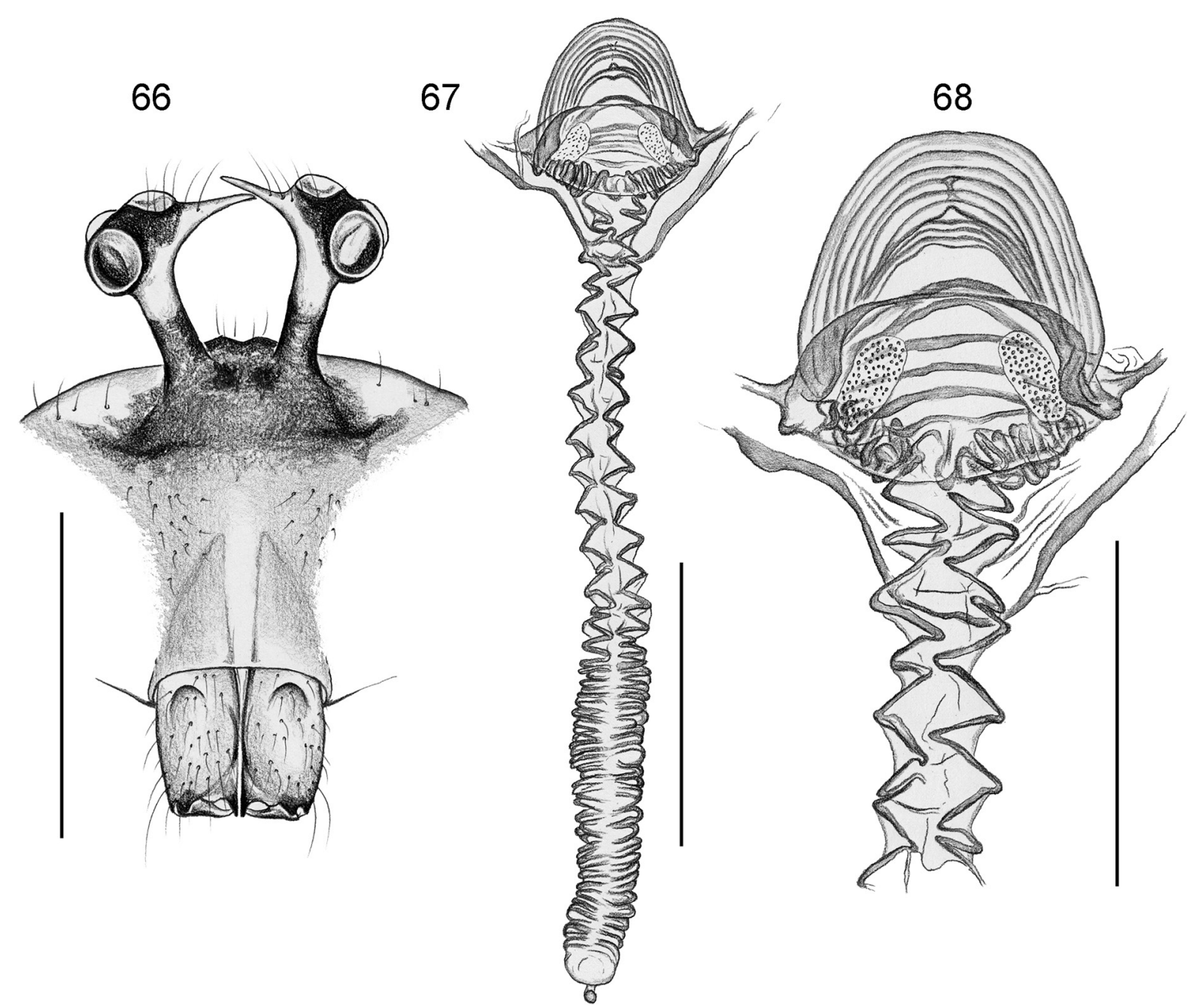

Figs 66-68. Panjange hamiguitan Huber sp. nov. (ZFMK, Ar 13009, 13012). 66. Male prosoma and chelicerae, frontal view. 67. Cleared female genitalia, dorsal view (proximal part of scape partly extended). 68. Detail of Fig. 67. Scale bars: $66-67=0.5 \mathrm{~mm} ; 68=0.3 \mathrm{~mm}$. 


\section{Panjange isarog Huber sp. nov. urn:1sid:zoobank.org:act:AEDDA6F2-E310-4FAA-873D-A001878505A2}

Figs 69-73

\section{Diagnosis}

Easily distinguished from closest known relatives (Pa. marilog Huber sp. nov.; Pa. dinagat Huber sp. nov.) by processes arising from near male PME with widened tips (Fig. 71), by morphology of male palp (Figs 69, 70; simple retrolatero-ventral trochanter apophysis; procursus with transparent dorsal flap; appendix with simple tip, short and evenly curved), and by epigynal scape without widening in mid-section (Fig. 72). From other congeners also by male clypeus modification (Fig. 71; patch of $\sim 25$ short spines), and by epigynal scape directed toward anterior (Fig. 72).

\section{Etymology}

The species name is derived from the type locality; noun in apposition.

\section{Type material}

PHILIPPINES: holotype $\widehat{\jmath}$, in ZFMK (Ar 13013), Luzon, Camarines Sur Province, Mt. Isarog, W slope $\left(13.664^{\circ} \mathrm{N}, 123.34-123.35^{\circ} \mathrm{E}\right), \sim 600-900 \mathrm{~m}$ a.s.l., forest, on leaves, $23 \mathrm{Feb} .2014$ (B.A. Huber).

\section{Other material examined}

PHILIPPINES: 2 $q$ in ZFMK (Ar 13014), same data as holotype.

\section{Description}

Male (holotype)

MeAsurements. Total body length 5.2, carapace width 1.1. Leg 1: $38.8(8.9+0.5+9.1+18.3+2.0)$, tibia 2: 6.1, tibia 3: 3.6, tibia 4: 5.5; tibia 1 L/d: 98. Distance PME-PME $450 \mu \mathrm{m}$, diameter PME $90 \mu \mathrm{m}$, distance PME-ALE $40 \mu \mathrm{m}$; AME absent.

CoLor. Carapace pale ochre yellow to whitish, without posterior mark, ocular area and clypeus dark brown, with black mark in AME area; sternum whitish; legs ochre-yellow with dark brown patellae and tibia-metatarsus joints; abdomen ochre-gray, with black marks dorsally, monochromous ventrally.

Body. Habitus similar to Pa. marilog Huber sp. nov. and Pa. dinagat Huber sp. nov. (cf. Figs 11, 14); ocular area raised, each triad on long stalk, curved process arising from near PME with distinctive widened tip directed toward anterior (Fig. 71); carapace without median furrow; clypeus with distinct field of $\sim 25$ short spines, with slightly longer but not stronger hairs below black mark; sternum wider than long $(0.70 / 0.55)$, unmodified.

Chelicerae. As in Fig. 71, with pair of simple, weakly sclerotized processes in rather frontal position directed toward median; without modified hairs; without stridulatory ridges.

Palps. As in Figs 69-70; symmetric; coxa with strong ventro-distal rim but otherwise unmodified; trochanter relatively long, with two simple retrolateral processes; femur short, with two short dorsal processes; tibia short and wide (width $\sim 65 \%$ of length); tarsus with short whitish elongation with subterminal tarsal organ; procursus proximal part with pointed ventral process, distal part hinged, very complex, with distinctive dorsal transparent flap; bulb with strong proximal sclerite, with processes extending in opposite directions (dorsal embolus; ventral appendix with many small scales), with small retrolateral toothed process arising from proximal bulbal sclerite, without small round sclerite between appendix and bulb. 


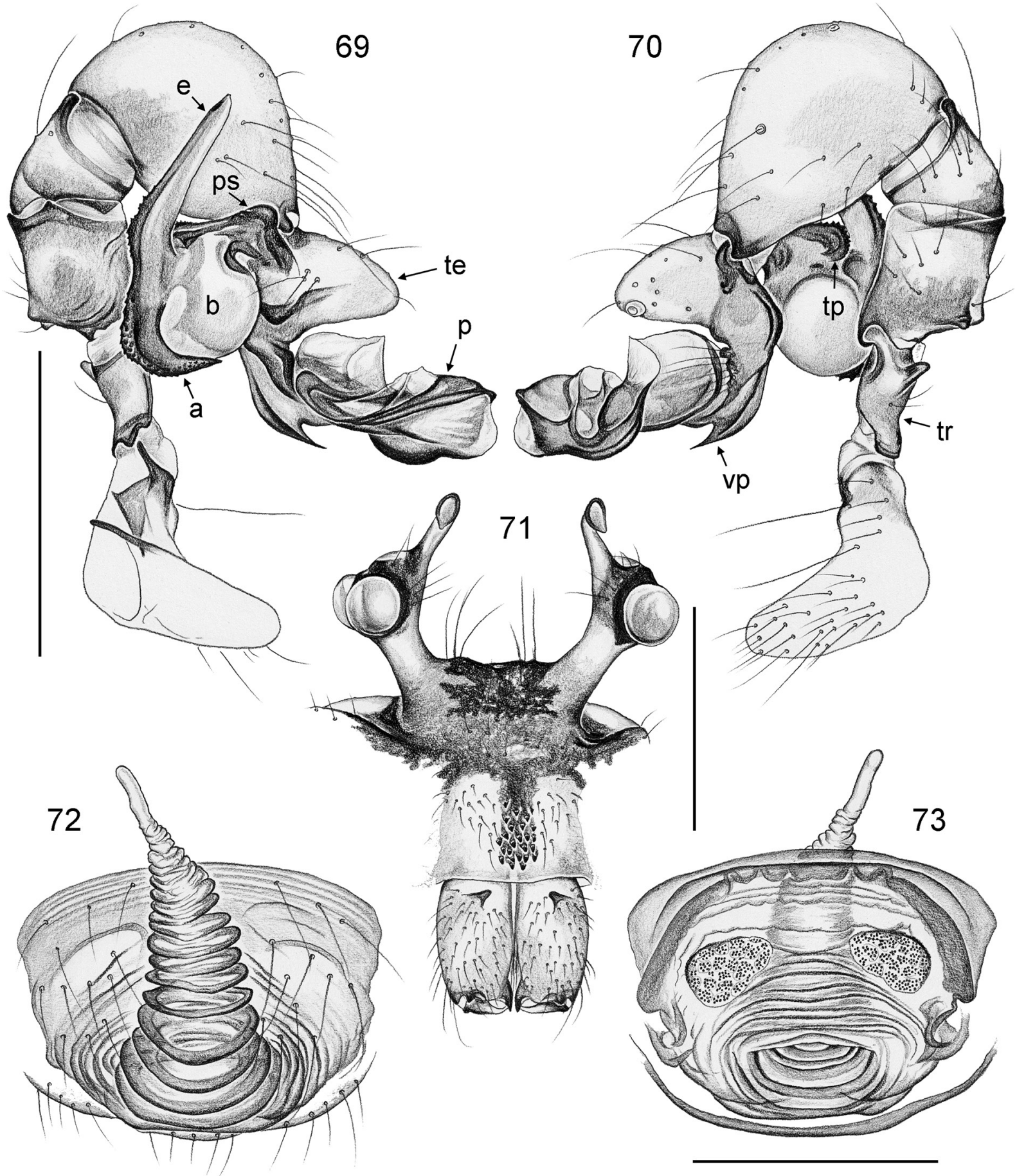

Figs 69-73. Panjange isarog Huber sp. nov. (ZFMK, Ar 13013, 13014). 69-70. Left male palp, prolateral and retrolateral views. 71. Male prosoma and chelicerae, frontal view. 72-73. Cleared female genitalia, ventral and dorsal views. Abbreviations: $\mathrm{a}=$ appendix; $\mathrm{b}=$ genital bulb; $\mathrm{e}=$ embolus; $\mathrm{p}=$ procursus; ps = proximal bulbal sclerite; te $=$ tarsal elongation; $t p=$ toothed process of proximal bulbal sclerite; tr $=$ trochanter. Scale bars: $69-71=0.5 \mathrm{~mm} ; 72-73=0.3 \mathrm{~mm}$. 
LEGS. Without spines and curved hairs; few vertical hairs; retrolateral trichobothrium on tibia 1 at $2 \%$; prolateral trichobothrium absent on tibia 1, present on other tibiae; tarsus 1 with $>30$ pseudosegments, only distally distinct.

\section{Female}

In general similar to male but eye triads on low humps and much closer together (distance PME-PME $250 \mu \mathrm{m}$ ); clypeus unmodified. Tibia 1: 6.9, 7.4. Epigynum very small, weakly sclerotized plate with scape directed toward anterior, scape strongly folded, apparently extensible, without widening in midsection (Fig 72); internal genitalia as in Fig. 73.

\section{Distribution}

Known from type locality on Luzon Island only (Fig. 16).

Panjange dinagat Huber sp. nov. urn:1sid:zoobank.org:act:A711003E-5B76-4450-B9EE-C618A2200483

Figs 11-13, 74-78

\section{Diagnosis}

Easily distinguished from most known relatives (except $P a$. marilog Huber sp. nov.) by complex male palpal trochanter apophysis (Fig. 75), and by widening of epigynal scape in mid-section (Fig. 77); from Pa. marilog Huber sp. nov. by male pedipalp (Figs 74-75; relatively wider tibia; shorter whitish elongation of tarsus; different shapes of procursus and appendix; more slender embolus) and female genitalia (longer than wide; Fig. 77).

\section{Etymology}

The species name is derived from the type locality; noun in apposition.

\section{Type material}

PHILIPPINES: holotype $\widehat{~}$, in ZFMK (Ar 13015), Dinagat Island, near Libjo, Paragua Forest, "site 1" $\left(10.222^{\circ} \mathrm{N}, 125.553^{\circ} \mathrm{E}\right), 130 \mathrm{~m}$ a.s.1., forest at brook, on leaves, 20 Feb. 2014 (B.A. Huber, P.N. Banaag).

\section{Other material examined}

PHILIPPINES, Dinagat Island: 1 ô, 3 q $q, 2$ juvs in ZFMK (Ar 13016), same data as holotype; 1 , 2 juvs in pure ethanol, in ZFMK (Phi 232), same data; 1 \% in ZFMK (Ar 13017), near Libjo, Paragua Forest, "site 2 " $\left(10.241^{\circ} \mathrm{N}, 125.545^{\circ} \mathrm{E}\right), 240 \mathrm{~m}$ a.s.l., forest along brook, on leaf, $20 \mathrm{Feb} .2014$ (B.A. Huber, P.N. Banaag).

\section{Description}

\section{Male (holotype)}

MEasurements. Total body length 4.4, carapace width 1.0. Leg 1: $33.9(7.8+0.5+7.9+15.7+2.0)$, tibia 2: 5.0, tibia 3: 2.8, tibia 4: 4.3; tibia 1 L/d: 97. Distance PME-PME $430 \mu \mathrm{m}$, diameter PME $90 \mu \mathrm{m}$, distance PME-ALE $\sim 50 \mu \mathrm{m}$; AME absent.

CoLor. Carapace pale ochre yellow to whitish, without posterior mark, ocular area and clypeus dark brown, with black mark in AME area; sternum whitish; legs ochre-yellow with dark brown patellae and tibia-metatarsus joints; abdomen ochre-gray, with black marks dorsally, monochromous ventrally.

Body. Habitus as in Fig. 11; ocular area raised, each triad on long stalk, with pointed curved process arising from near PME and directed toward anterior (Fig. 76); carapace without median furrow; clypeus 


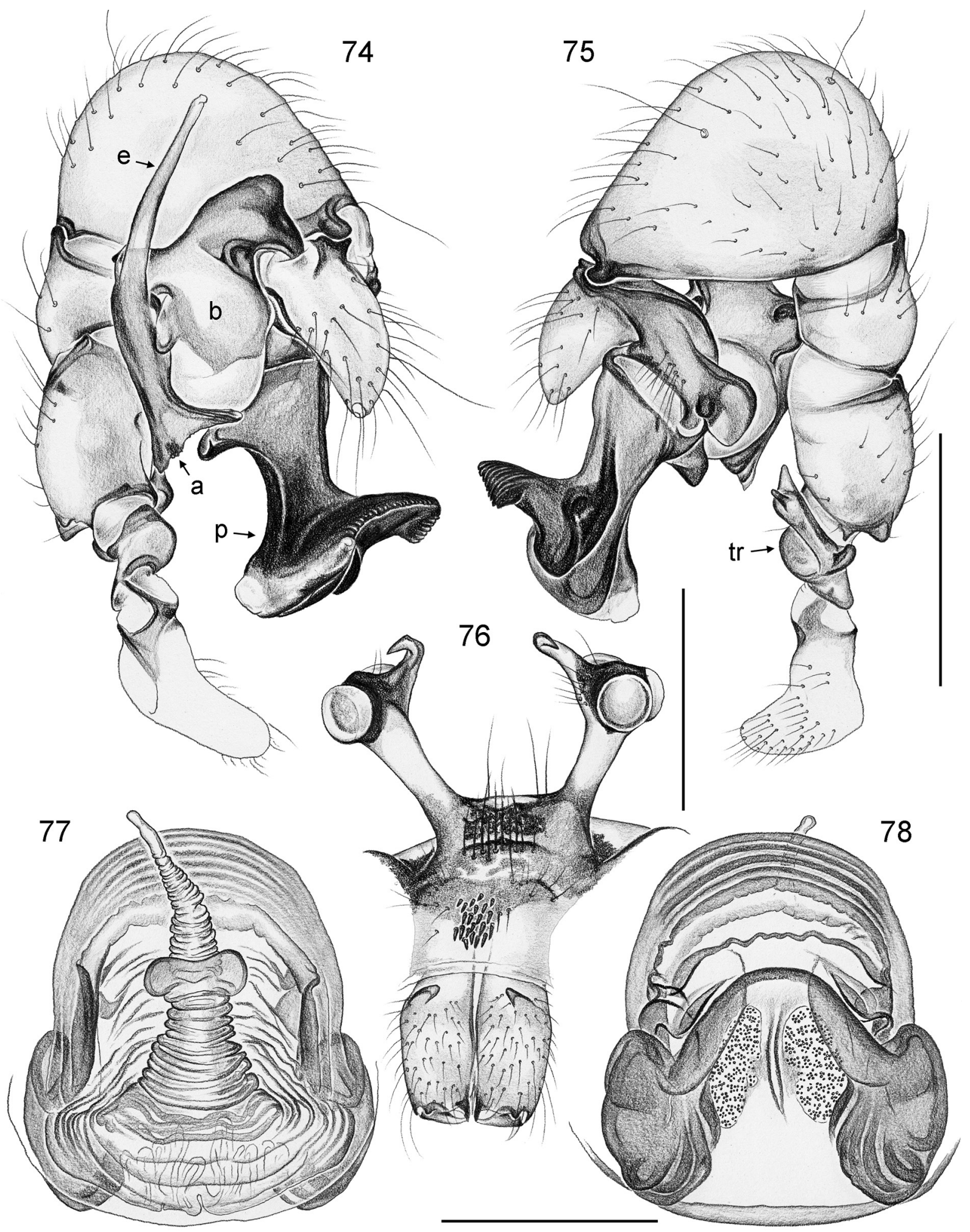

Figs 74-78. Panjange dinagat Huber sp. nov. (ZFMK, Ar 13016). 74-75. Left male palp, prolateral and retrolateral views. 76. Male prosoma and chelicerae, frontal view. 77-78. Cleared female genitalia, ventral and dorsal views. Abbreviations: $\mathrm{a}=$ appendix; $\mathrm{b}=$ genital bulb; $\mathrm{e}=$ embolus; $\mathrm{p}=$ procursus; $\operatorname{tr}=$ trochanter. Scale bars: $74-76=0.5 \mathrm{~mm} ; 77-78=0.3 \mathrm{~mm}$. 
with two patches of modified hairs: slightly stronger hairs below black mark and distinct field of $\sim 20$ short spines more distally; sternum wider than long $(0.65 / 0.50)$, unmodified.

Chelicerae. As in Fig. 76, with pair of simple, weakly sclerotized processes in rather frontal position directed toward median; without modified hairs; without stridulatory ridges.

PaLPS. As in Figs 74-75; symmetric; coxa with strong ventro-distal rim but otherwise unmodified; trochanter relatively long, with simple retrolatero-dorsal process and complex retrolatero-ventral apophysis, distally curved toward prolateral, with two distinctive subdistal branches directed toward distal and retrolateral respectively; femur short, with two short dorsal processes and very indistinct prolateral hump; tibia very thick (width $\sim 70 \%$ of length); tarsus with short whitish elongation with terminal tarsal organ; procursus proximal part with rounded ventral process, distal part hinged, with distinctive retrolateral process and simple flat prolateral process; bulb with strong proximal sclerite, long processes extending in opposite directions (dorsal embolus; ventral appendix), with retrolateral toothed process arising from proximal bulbal sclerite, with small round sclerite between appendix and bulb.

LEGS. Without spines and curved hairs; few vertical hairs; retrolateral trichobothrium on tibia 1 at $2 \%$; prolateral trichobothrium absent on tibia 1, present on other tibiae; tarsus 1 pseudosegments barely visible in dissecting microscope.

Male (variation)

Tibia 1 in other male: 7.8 .

\section{Female}

In general similar to male but eye triads on low humps and much closer together (distance PME-PME $220 \mu \mathrm{m}$ ); clypeus unmodified. Tibia 1 in 4 females: 5.9, 6.1, 6.1, 6.7. Epigynum weakly sclerotized plate with scape directed toward anterior, scape strongly folded and extensible, with distinctive widening in mid-section (Fig. 77), distal part semitransparent; internal genitalia as in Fig. 78.

\section{Natural history}

The spiders were found on the undersides of large leaves about $0.5-2 \mathrm{~m}$ above the ground.

\section{Distribution}

Known from type locality on Dinagat Island only (Fig. 16).

Panjange marilog Huber sp. nov. urn:1sid:zoobank.org:act:0B086DBA-DB8C-4253-AB9C-E932F2697216

Figs $14-15,79-89$

\section{Diagnosis}

Easily distinguished from most known relatives (except $P a$. dinagat Huber sp. nov.) by complex male palpal trochanter apophysis (Fig. 80), and by widening of epigynal scape in mid-section (Fig. 82); from $P a$. dinagat Huber sp. nov. by male pedipalp (Figs 79-80; relatively more slender tibia; longer whitish elongation of tarsus; different shapes of procursus and appendix; wider embolus) and female genitalia (wider than long; Fig. 82).

\section{Etymology}

The species name is derived from the type locality; noun in apposition. 


\section{Type material}

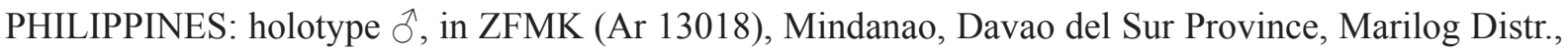
Baganihan $\left(7.469^{\circ} \mathrm{N}, 125.250^{\circ} \mathrm{E}\right), 1210 \mathrm{~m}$ a.s.l., primary forest near road, on leaves, $15 \mathrm{Feb} .2014$ (B.A. Huber, E. Mondejar).

\section{Other material examined}

PHILIPPINES: Davao del Sur Province: $4 \hat{\delta} \hat{\partial}, 1 q$ in ZFMK (Ar 13019) and $1 \hat{\delta}$ in MSU-IIT, same data as holotype; 2 + 9,3 juvs in pure ethanol, in ZFMK (Phi 255), same data; 10,1 i in ZFMK (Ar 13020), same locality, "site 2" $\left(7.4563^{\circ} \mathrm{N}, 125.2390^{\circ} \mathrm{E}\right), 6$ Dec. 2014 (M.A. Responte); 1 ㅅ, 2 우, 3 juvs in ZFMK (Ar 13021) and 1 \%, 1 ○ in MSU-IIT, same locality, "site 3" $\left(7.4696^{\circ} \mathrm{N}, 125.2452^{\circ} \mathrm{E}\right), 7$ Dec. 2014 (M.A. Responte). Bukidnon Province: $2 \hat{\jmath} \hat{\partial}, 4$ 우, 7 juvs in ZFMK (Ar 13022) and $1 \hat{\jmath}, 1$ ㅇ in MSU-IIT, all poorly preserved, Imbayao ( $\left.8.1344^{\circ} \mathrm{N}, 125.0297^{\circ} \mathrm{E}\right), 9-10$ Feb. 2015 (E.P. Mondejar).

\section{Description}

\section{Male (holotype)}

Measurements. Total body length 5.1, carapace width 1.2. Leg 1: $41.2(9.6+0.5+9.7+19.1+2.3)$, tibia 2: 6.5, tibia 3: 3.8, tibia 4: 5.7; tibia $1 \mathrm{~L} / \mathrm{d}$ : 97. Distance PME-PME $470 \mu \mathrm{m}$, diameter PME $90 \mu \mathrm{m}$, distance PME-ALE $~ 50 \mu \mathrm{m}$; AME absent.

CoLOR. Carapace pale ochre yellow to whitish, without posterior mark, ocular area and clypeus dark brown, with black mark in AME area; sternum whitish; legs ochre-yellow with dark brown patellae and tibia-metatarsus joints; abdomen ochre-gray, with black marks dorsally, monochromous ventrally.

Body. Habitus as in Fig. 14; ocular area raised, each triad on long stalk, with pointed curved process arising from near PME and directed toward anterior (Figs 81, 84, 87); carapace without median furrow; clypeus with two patches of modified hairs: slightly stronger hairs below black mark and distinct field of $\sim 20$ short spines more distally (Figs 84-85); sternum wider than long $(0.70 / 0.60)$, unmodified.

Chelicerae. As in Figs 81 and 84, with pair of simple, weakly sclerotized processes in rather frontal position directed toward median; without modified hairs; without stridulatory ridges.

PaLPS. As in Figs 79-80; symmetric; coxa with strong ventro-distal rim but otherwise unmodified; trochanter relatively long, with simple retrolatero-dorsal process and complex retrolatero-ventral apophysis distally curved toward prolateral, with two distinctive subdistal branches directed toward distal and retrolateral respectively; femur short, with two short dorsal processes and indistinct prolateral hump; tibia very thick (tibia width $\sim 60 \%$ of length); tarsus with whitish elongation with terminal capsulate tarsal organ (Fig. 89); procursus proximal part with ventral process, distal part hinged, with distinctive retrolateral process and simple flat prolateral process; bulb with strong proximal sclerite, long processes extending in opposite directions (dorsal embolus; ventral appendix), with retrolateral process arising from proximal bulbal sclerite, with small round sclerite between appendix and bulb.

LEGs. Without spines and curved hairs; few vertical hairs; retrolateral trichobothrium on tibia 1 at 2\%; prolateral trichobothrium absent on tibia 1, present on other tibiae; tarsus 1 with $>30$ pseudosegments, only distally fairly distinct.

Male (variation)

Tibia 1 in 10 other males: 9.2-10.4 (mean 9.6). Background color of abdomen with variable shades of reddish to light brown (Figs 14-15). 


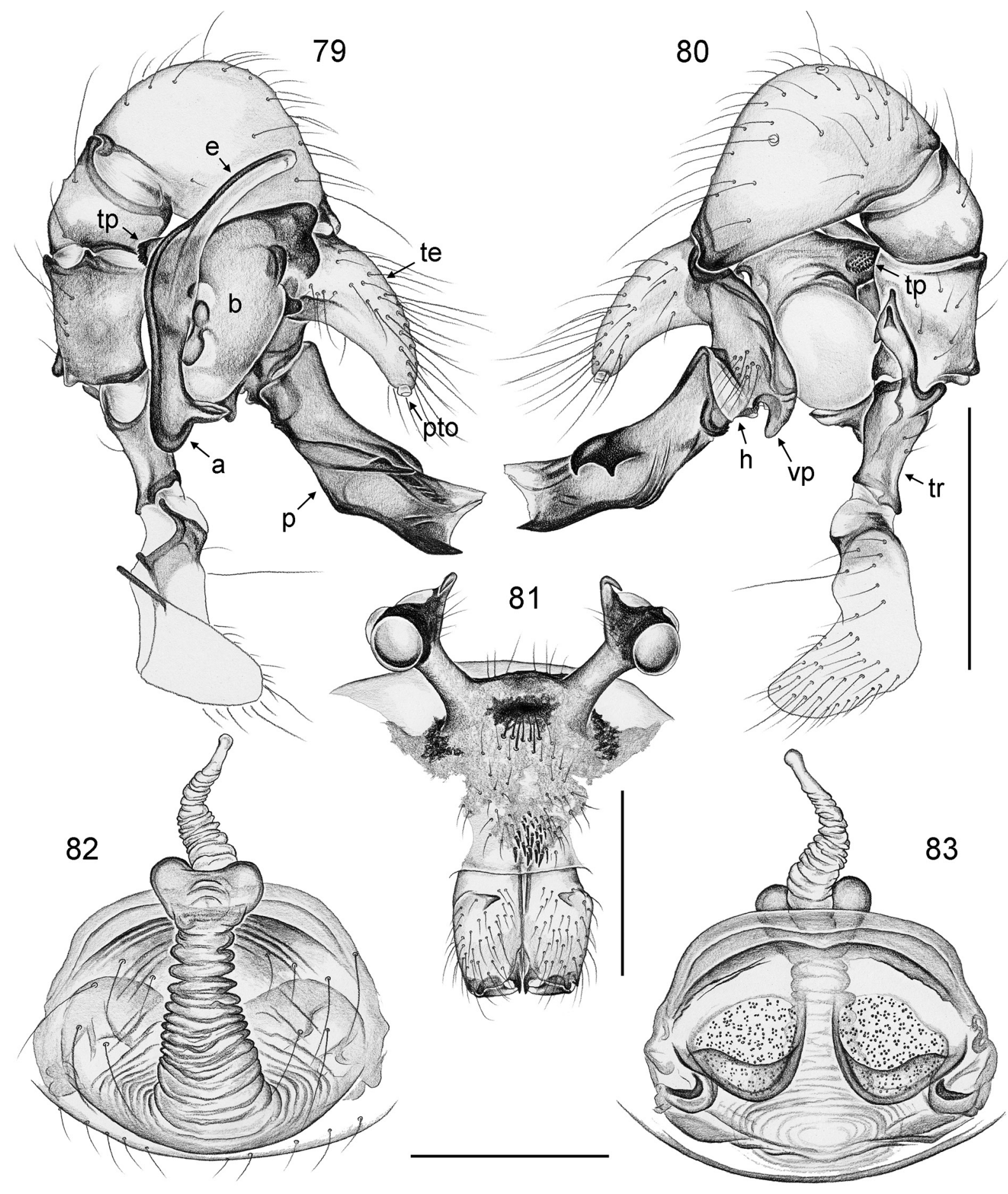

Figs 79-83. Panjange marilog Huber sp. nov. (ZFMK, Ar 13019) 79-80. Left male palp, prolateral and retrolateral views. 81. Male prosoma and chelicerae, frontal view. 82-83. Cleared female genitalia, ventral and dorsal views. Abbreviations: $\mathrm{a}=$ appendix; $\mathrm{b}=$ genital bulb; $\mathrm{e}=$ embolus; $\mathrm{h}=$ hinge; $\mathrm{p}=$ procursus; $\mathrm{pto}=$ palpal tarsal organ; te $=$ tarsal elongation; $\mathrm{t}=$ toothed process of proximal bulbal sclerite; $\operatorname{tr}=$ trochanter; $\mathrm{vp}=$ ventral process. Scale bars: $79-81=0.5 \mathrm{~mm} ; 82-83=0.3 \mathrm{~mm}$. 

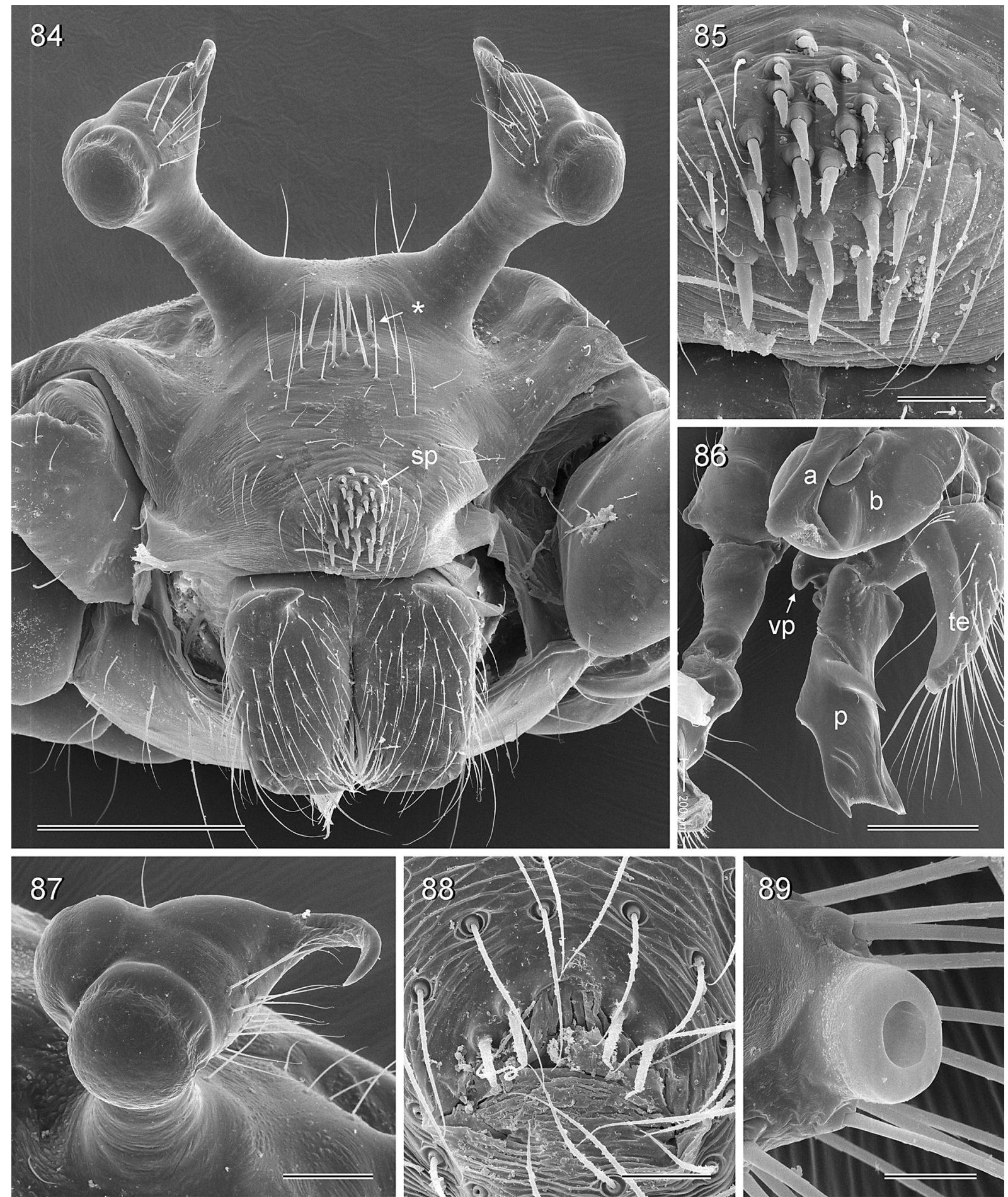

Figs 84-89. Panjange marilog Huber sp. nov., SEM micrographs (ZFMK, Ar 13019). 84. Male prosoma, frontal view (asterisk marks stronger hairs below ocular area). 85. Spines on male clypeus. 86. Left male palp, prolateral view. 87. Right eye stalk, triad, and hooked process, oblique frontal view. 88. Male gonopore. 89. Male palpal tarsal organ. Abbreviations: $a=$ appendix; $b=$ genital bulb; $p=$ procursus; te $=$ tarsal elongation; $\mathrm{sp}=$ spines on clypeus; $\mathrm{vp}=$ ventral process. Scale bars: $84=300 \mu \mathrm{m} ; 85=40 \mu \mathrm{m}$; $86=200 \mu \mathrm{m} ; 87=80 \mu \mathrm{m} ; 88=30 \mu \mathrm{m} ; 89=20 \mu \mathrm{m}$. 


\section{Female}

In general similar to male but eye triads on low humps and much closer together (distance PME-PME $240 \mu \mathrm{m}$ ); clypeus unmodified. Tibia 1 in 4 females: 7.1, 7.3, 7.3, 7.5. Epigynum weakly sclerotized plate with scape directed toward anterior, scape strongly folded, apparently extensible, with distinctive widening in mid-section (Fig. 82), distal part semitransparent; internal genitalia as in Fig. 83.

\section{Natural history}

The spiders were found on the undersides of leaves about $0.5-1 \mathrm{~m}$ above the ground.

\section{Distribution}

Known from two localities on Mindanao Island (Fig. 16).

Panjange bukidnon Huber sp. nov. urn:lsid:zoobank.org:act:1B7C5428-F2F6-49B6-BC90-79B2C761F2B7

Figs $90-92$

\section{Diagnosis}

Easily distinguished from known congeners (and other similar relatives currently in Pholcus) by modifications of male ocular area (Fig. 90; short stalks and distinctive processes arising from near PME, with contiguous pointed tips), and by morphology of male palp (Figs 91-92; highly distinctive procursus; shapes of bulbal processes). Female unknown.

\section{Etymology}

The species name is derived from the type locality; noun in apposition.

\section{Type material}

PHILIPPINES: holotype $\hat{\delta}$, in ZFMK (Ar 13023), Mindanao, Bukidnon Province, Santo Domingo $\left(7.782^{\circ} \mathrm{N}, 125.397^{\circ} \mathrm{E}\right), 560 \mathrm{~m}$ a.s.l., forest remnant along brook, on leaf, 8-9 Feb. 2014 (B.A. Huber, E. Mondejar).

\section{Other material examined}

None.

\section{Description}

\section{Male (holotype)}

Measurements. Total body length 5.0, carapace width 0.9. Leg 1: $9.8+0.4+9.8$, metatarsi broken in both legs, tibia 2: 6.4, tibia 3: 3.7, tibia 4: 5.4; tibia $1 \mathrm{~L} / \mathrm{d}$ : 110. Distance PME-PME $250 \mu \mathrm{m}$, diameter PME $100 \mu \mathrm{m}$, distance PME-ALE $\sim 30 \mu \mathrm{m}$; AME absent.

COLOR. Entire spider mostly pale ochre-gray to whitish, except large dark brown mark in ocular area including clypeus, pair of indistinct dark marks posteriorly on carapace, few small dark spots on abdomen dorsally, and brown patellae and tibia-metatarsus joints.

Body. Habitus similar to Pa. malagos Huber sp. nov. (cf. Fig. 5); ocular area raised, each triad on short stalk, with distinctive processes arising from near PME with contiguous tips (Fig. 90); carapace without median furrow; clypeus unmodified; sternum wider than long $(0.65 / 0.55)$, unmodified.

Chelicerae. As in Fig. 90, with pair of simple, weakly sclerotized proximal processes in rather frontal position; each lamina with additional small tooth; without modified hairs; without stridulatory ridges. 
PALPS. As in Figs 91-92; symmetric; coxa with distinct ventral apophysis; trochanter with short retrolateral apophysis; femur small, barely modified; tibia very large and wide (width $\sim 65 \%$ of length); tarsus without elongation; procursus proximal part very short, without ventral process, distal part hinged, very large, without (or with very indistinct) parallel ridges; bulb with strong proximal sclerite, with very

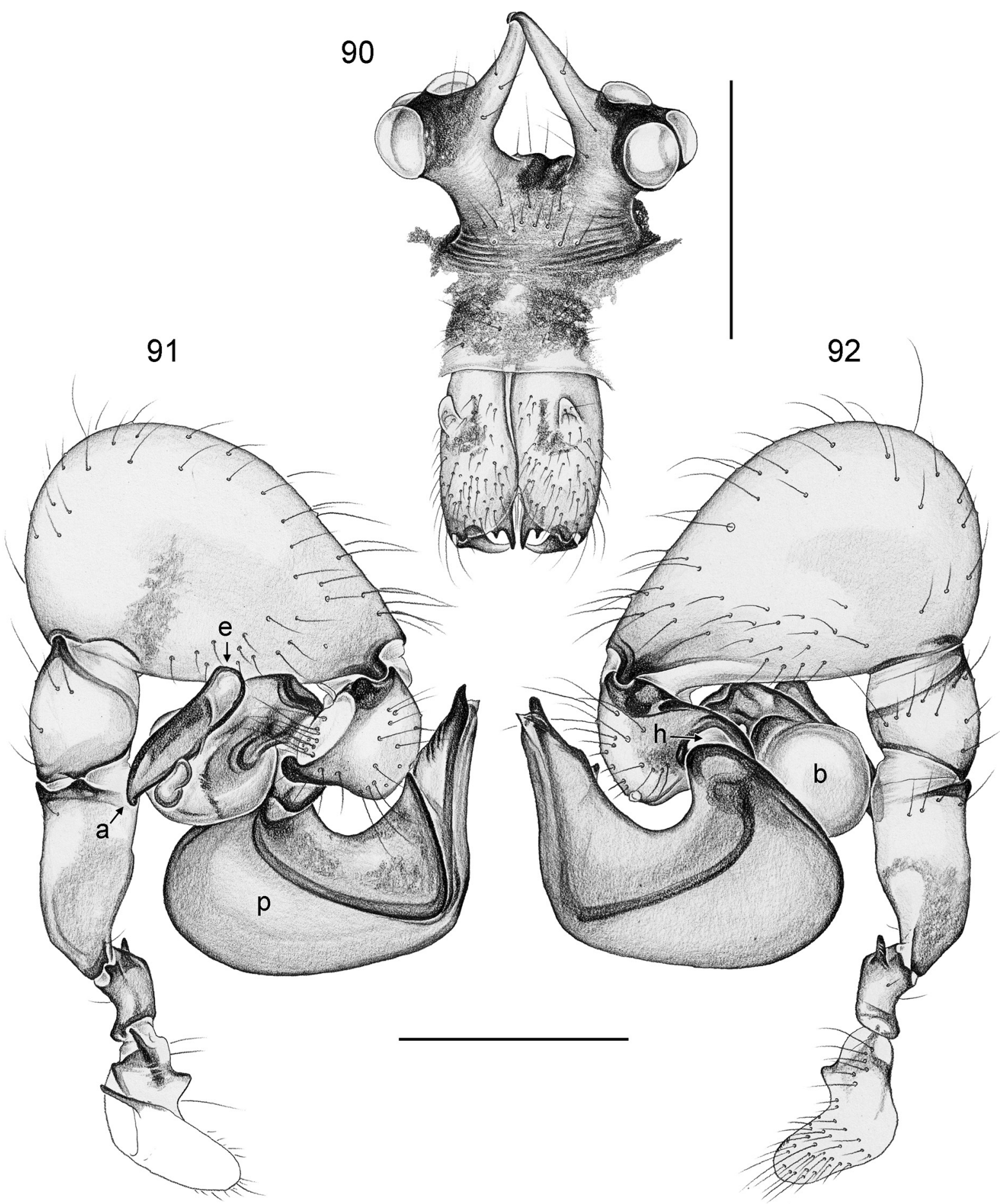

Figs 90-92. Panjange bukidnon Huber sp. nov. (ZFMK, Ar 13023). 90. Male prosoma and chelicerae, frontal view. 91-92. Left male palp, prolateral and retrolateral views. Abbreviations: $a=$ appendix; $\mathrm{b}=$ genital bulb; $\mathrm{e}=$ embolus; $\mathrm{h}=$ hinge; $\mathrm{p}=$ procursus. Scale bars $=0.5 \mathrm{~mm}$. 
short processes (embolus and appendix) extending in opposite directions, without retrolateral process arising from proximal bulbal process, with small round sclerite between appendix and bulb.

LEGS. Without spines and curved hairs; few vertical hairs; retrolateral trichobothrium on tibia 1 at $4 \%$; prolateral trichobothrium absent on tibia 1, present on other tibiae.

\section{Female}

Unknown.

\section{Distribution}

Known from type locality on Mindanao Island only (Fig. 16).

\section{Discussion}

The Panjange lanthana group, previously monotypic (Deeleman-Reinhold \& Platnick 1986; Huber 2011), is a diverse group apparently restricted to the Philippines and supported by two synapomorphies. The configuration of the male bulbal sclerites (embolus pointing in opposite direction than appendix) is unique among Pholcidae. A close relationship of the lanthana group with the widespread cavicola group (Sulawesi to Australia) is strongly supported by the cladistic analysis. However, the relationship of these two groups to the third species group (nigrifrons group on Borneo) remains unclear. The characters supporting the monophyly of Panjange do not appear particularly convincing: (1) the reduction of the uncus has occurred repeatedly within Pholcus (Huber 2011); and (2) the ridges on the procursus are barely visible or absent in some species. In fact, preliminary molecular data (A. Valdez-Mondragón, D. Dimitrov, B.A. Huber unpublished data) suggest Panjange might not be monophyletic.

Spider genital asymmetry is apparently exceedingly rare, and to our knowledge has been documented in only nine of currently 3959 extant spider genera (genus count from World Spider Catalog 2015). Most cases are in Pholcidae (independent origins in Mesabolivar González-Sponga, 1998, Metagonia Simon, 1893, and Panjange; Huber 1997b, 2004, 2006; herein), and Oonopidae (presumably independent origins in Lionneta Benoit, 1979, Escaphiella Platnick \& Dupérré, 2009, Aschnaoonops Makhan \& Ezzatpanah, 2011, and Paradysderina Platnick \& Dupérré, 2011; Burger 2010; Platnick \& Dupérré 2009, 2011; Platnick et al. 2013). Further cases have been reported in Theridiidae (Asygyna Agnarsson, 2006; Agnarsson 2006) and Oxyopidae (Oxyopes Latreille, 1804; Brady 1964, 1975). An attempt to explain the rarity of this phenomenon in spiders (as opposed to the ubiquity in insects) was made in Huber et al. (2007). This explanation centers on the fact that one-sided mating positions are an option for neopteran insects with their unpaired intromittent organ but not for spiders with their paired palps. While this may explain the rarity in spiders, it does not explain those few cases where asymmetry did evolve. A previous idea, that spider asymmetry may usually originate in the female as a result of space constraints (Huber 2004, 2006; Huber et al. 2007) may apply to certain taxa (e.g., Asygyna, Mesabolivar, Metagonia) but apparently not to others. In Oonopidae, most cases of asymmetry seem to be restricted to males. However, routine preparations of female internal genitalia may simply fail to reveal subtle asymmetries. In fact, the only oonopid case of female asymmetry was discovered by serial sectioning and SEM of internal structures (Burger 2010). The same may apply to the three Panjange spiders with male asymmetric genitalia described herein. In two of them (Pa. malagos Huber sp. nov.; Pa. camiguin Huber sp. nov.), the female genitalia appear symmetric; in the third (Pa. casaroro Huber sp. nov.), it is not clear if the apparent asymmetry is an artifact of preparation or not. Further anatomical study with adequate sample sizes is needed to evaluate female symmetry $v s$. asymmetry in these species.

Sexually dimorphic eye-stalks have been studied in much detail in stalk-eyed flies (e.g., Burkhardt \& de la Motte 1988; Wilkinson \& Dodson 1997; Panhuis \& Wilkinson 1999; Baker \& Wilkinson 2001). For these insects, the general consensus is that sexual selection in the context of a resource-defense 
mating system has been the driving force in the repeated evolution of exaggerated male eye stalks, both by male-male competition and by female choice. In linyphiid spiders, modifications of the male "head" are apparently always accompanied by glands that discharge their products through pores easily visible in the SEM (Schaible et al. 1986). Sexual selection by female choice (via gustatorial courtship) is the most plausible explanation for this group of spiders (Vanacker et al. 2003; Kunz et al. 2012), but the few species with real eye stalks (such as Walckenaeria acuminata Blackwall, 1833) have never been studied in detail. The same is unfortunately true of certain theridiid spiders with similar long eye stalks [e.g., Phoroncidia longiceps (Keyserling, 1886); see Levi 1964]. In Pholcidae, nothing is known about the use of the highly sexually dimorphic eye stalks. Glands and pores have been found in the male eye turrets of Modisimus culicinus (Simon, 1893) (Huber 1997a) but in none of the Panjange spiders studied herein and in none of the stalk-eyed Pholcus studied previously with the SEM (Huber 2011). Neither fights nor matings have ever been observed in any Panjange species or in any stalk-eyed Pholcus. The facts that these spiders were hard to find at all localities and that the low abundance seemed to result from the rarity of suitable large leaves suggest that a resource-defense mating system like in stalk-eyed flies is a plausible working hypothesis for future studies.

Elongated genital structures in spiders are widespread, but it is usually the male intromittent structures and the corresponding female internal ducts that become long and exaggerated. In most cases, this concerns the sperm transfer organ (the embolus) and the corresponding insemination ducts (reviewed in Eberhard \& Huber 2010). However, other intromittent structures may go through analogous developments, as for example male procursus and female uterus externus folds in Mesabolivar yuruani (Huber, 2000) (see Huber 2006; under Kaliana yuruani); or male tibia apophysis and a novel female tubular system in Hortipes gigapophysalis Jocqué, Bosselaers \& Henrard, 2012 (Jocqué et al. 2012). In Filistatidae, it is the basal palpal segments rather than the intromittent embolus that may become elongated (Marusik \& Zamani 2015). In this group, cannibalism might appear a plausible explanation because the long palp allows the male body to remain out of reach for the female jaws (e.g., Gerhardt 1928, fig. 2). However, observations have suggested female cooperation rather than aggression (Gerhard 1928, 1930). In Panjange spiders, elongation likewise involves male structures that are very likely not inserted into the female. Instead, the palpal elongation in this group appears related to the extensible scape in the female. Both in Calapnita and in Panjange, the species with the longest male palps also have the longest female scapes (Calapnita semengoh Huber, 2011; Pa. hamiguitan Huber sp. nov.). This suggests that males and females may be engaged in an arms race (cf. Kuntner et al. 2009), with ever longer scapes requiring ever longer palps. The fact that pholcid chelicerae contact the female during copulation in all cases studied (reviewed in Huber 1999) suggests that palpal elongation is not related to cannibalism avoidance by keeping the body far from the female. In sum, a wide variety of factors may lead to genital elongation in spiders, but direct functional observations are almost entirely missing.

\section{Acknowledgements}

We thank our driver Vicente Bulongon for bringing us safely to all requested places; the students Mae A. Responte, Maria B.R. Dacar, Eddie P. Mondejar and Philip N.O. Banaag II for help in the field and for contributing specimens from their own research; Matjaz Kuntner and an anonymous reviewer for comments that helped improve the manuscript; the Department of Environment and Natural Resources (DENR) CARAGA, DENR Region X, and DENR Region XI for issuing the relevant permits; and the German Research Foundation for financial support (DFG Project HU 980/11-1).

\section{References}

Agnarsson I. 2006. Asymmetric female genitalia and other remarkable morphology in a new genus of cobweb spiders (Theridiidae, Araneae) from Madagascar. Biological Journal of the Linnean Society 87: 211-232. http://dx.doi.org/10.1111/j.1095-8312.2006.00569.x 
Baker R.H. \& Wilkinson G.S. 2001. Phylogenetic analysis of sexual dimorphism and eye-span allometry in stalk-eyed flies (Diopsidae). Evolution 55 (7): 1373-1385. http://dx.doi.org/10.1111/j.0014-3820.2001. $\underline{\mathrm{tb} 00659 . x}$

Barnes R.S.K. 1968. On the evolution of elongated ocular peduncles in the Brachyura. Systematic Zoology 17: 182-187.

Bowman T.E. 1984. Stalking the wild crustacean: The significance of sessile and stalked eyes in phylogeny. Journal of Crustacean Biology 4: 7-11. http://dx.doi.org/10.2307/1547891

Brady A.R. 1964. The lynx spiders of North America, north of Mexico (Araneae: Oxyopidae). Bulletin of the Museum of comparative Zoology 131 (3): 429-518.

Brady A.R. 1975. The lynx spider genus Oxyopes in Mexico and Central America (Araneae: Oxyopidae). Psyche 82 (2): 189-243. http://dx.doi.org/10.1155/1975/24938

Brown B.V. 1993. A further chemical alternative to critical-point-drying for preparing small (or large) flies. Fly Times 11: 10.

Burger M. 2010. Complex female genitalia indicate sperm dumping in armored goblin spiders (Arachnida, Araneae, Oonopidae). Zoology 113: 19-32. http://dx.doi.org/10.1016/j.zool.2009.04.002

Burkhardt D. \& de la Motte I.1988. Big 'antlers' are favoured: female choice in stalk-eyed flies (Diptera, Insecta), field collected harems and laboratory experiments. Journal of Comparative Physiology A 162 (5): 649-652. http://dx.doi.org/10.1007/BF01342640

Deeleman-Reinhold C.L. 1986a. Leaf-dwelling Pholcidae in Indo-Australian rain forests. In: Eberhard W.G., Lubin Y.D. \& Robinson B.C. (eds) Proceedings of the Ninth International Congress of Arachnology, Panama 1983: 45-48. Smithsonian Institution Press, Washington.

Deeleman-Reinhold C.L. 1986b. Studies on tropical Pholcidae II. Redescription of Micromerys gracilis Bradley and Calapnita vermiformis Simon (Araneae, Pholcidae) and description of some related new species. Memoirs of the Queensland Museum 22 (2): 205-224.

Deeleman-Reinhold C.L. \& Deeleman P.R. 1983. Studies on tropical Pholcidae I. Panjange, a new genus of Indo-Australian leaf- and rock-dwelling pholcid spiders (Araneae). Zoologische Medelelingen 57 (14): 121-130.

Deeleman-Reinhold C.L. \& Platnick N.I. 1986. A new Panjange from northern Borneo (Araneae, Pholcidae). Journal of the New York Entomological Society 94 (4): 559-561.

Eberhard W.G. \& Huber B.A. 2010. Spider genitalia: precise maneuvers with a numb structure in a complex lock. In: Leonard J.L. \& Córdoba-Aguilar A. (eds) Evolution of Primary Sexual Characters in Animals: 249-284. Oxford University Press, Oxford, U.K.

Gerhardt U. 1928. Biologische Studien an griechischen, corsischen und deutschen Spinnen. Zeitschrift für Morphologie und Ökologie der Tiere 10 (4): 576-675. http://dx.doi.org/10.1007/BF00419324

Gerhardt U. 1930. Biologische Untersuchungen an südfranzösischen Spinnen. Zeitschrift für Morphologie und Ökologie der Tiere 19 (1): 184-227. http://dx.doi.org/10.1007/BF00412295

Goloboff P.A. 1993. NONA (NO NAME) ver. 2. Published by the author, Tucumán, Argentina. Available from http://www.lillo.org.ar/phylogeny/ [accessed 21 Nov. 2015]

Goloboff P.A. 1997. Pee-Wee, ver. 2.8. Published by the author, New York. Available from http://www. lillo.org.ar/phylogeny/ [accessed 21 Nov. 2015]

Goloboff P.A., Farris J.S. \& Nixon K. 2004. TNT, tree analysis using new technology, version 1.1. sponsored by the Willi Hennig Society. Available from http://www.lillo.org.ar/phylogeny/ [accessed 21 Nov. 2015] 
Goloboff P.A., Farris J.S. \& Nixon K. 2008. TNT, a free program for phylogenetic analysis. Cladistics 24 (5): 774-786. http://dx.doi.org/10.1111/j.1096-0031.2008.00217.x

Huber B.A. 1997a. Evidence for gustatorial courtship in a haplogyne spider (Hedypsilus culicinus: Pholcidae: Araneae). Netherlands Journal of Zoology 47 (1): 95-98. http://dx.doi.org/10.1163/156854297X00265

Huber B.A. 1997b. On American 'Micromerys' and Metagonia (Araneae, Pholcidae), with notes on natural history and genitalmechanics. Zoologica Scripta 25 (4):341-363.http://dx.doi.org/10.1111/j.1463-6409.1996. $\underline{\text { tb00170.x }}$

Huber B.A. 1999. Sexual selection in pholcid spiders (Araneae, Pholcidae): artful chelicerae and forceful genitalia. Journal of Arachnology 27 (1): 135-141.

Huber B.A. 2001. The pholcids of Australia (Araneae; Pholcidae): taxonomy, biogeography, and relationships. Bulletin of the American Museum of Natural History 260: 1-144. http://dx.doi. org/10.1206/0003-0090(2001)260<0001:TPOAAP $>2.0 . \mathrm{CO} ; 2$

Huber B.A. 2004. Evidence for functional segregation in the directionally asymmetric male genitalia of the spider Metagonia mariguitarensis (González-Sponga) (Pholcidae: Araneae). Journal of Zoology, London 262: 317-326. http://dx.doi.org/10.1017/S0952836903004709

Huber B.A. 2006. Cryptic female exaggeration: the asymmetric female internal genitalia of Kaliana yuruani (Araneae: Pholcidae). Journal of Morphology 276 (6): 705-712. http://dx.doi.org/10.1002/ jmor.10431

Huber B.A. 2010. Mating positions and the evolution of asymmetric insect genitalia. Genetica 138: 19-25. http://dx.doi.org/10.1007/s10709-008-9339-6

Huber B.A. 2011. Revision and cladistic analysis of Pholcus and closely related taxa (Araneae, Pholcidae). Bonner zoologische Monographien 58: 1-509.

Huber B.A. 2013. Revision and cladistic analysis of the Guineo-Congolian spider genus Smeringopina Kraus (Araneae, Pholcidae). Zootaxa 3713: 1-160. http://dx.doi.org/10.11646/zootaxa.3713.1.1

Huber B.A. \& Eberhard W.G. 1997. Courtship, copulation, and genital mechanics in Physocyclus globosus (Araneae, Pholcidae). Canadian Journal of Zoology 74: 905-918. http://dx.doi.org/10.1139/ z97-109

Huber B.A. \& Fleckenstein N. 2008. Comb-hairs on the fourth tarsi in pholcid spiders (Araneae, Pholcidae). Journal of Arachnology 36: 232-240. http://dx.doi.org/10.1636/CSh07-71.1

Huber B.A., Sinclair B. \& Schmitt M. 2007. The evolution of asymmetric genitalia in spiders and insects. Biological Reviews 82: 647-698. http://dx.doi.org/10.1111/j.1469-185X.2007.00029.x

Jocqué R., Bosselaers J. \& Henrard A. 2012. A new species of Hortipes (Araneae, Corinnidae), the first spider with an insertable retrolateral tibial apophysis on the male palp. European Journal of Taxonomy 26: 1-11. http://dx.doi.org/10.5852/ejt.2012.26

Kuntner M., Coddington J.A. \& Schneider J.M. 2009. Intersexual arms race? Genital coevolution in nephilid spiders (Araneae, Nephilidae). Evolution 63 (6): 1451-1463. http://dx.doi.org/10.1111/j.1558$\underline{5646.2009 .00634 . x}$

Kunz K., Garbe S. \& Uhl G. 2012. The function of the secretory cephalic hump in males of the dwarf spider Oedothorax retusus (Linyphiidae: Erigoninae). Animal Behaviour 83 (2): 511-517. http://dx.doi. org/10.1016/j.anbehav.2011.11.028

Levi H.W. 1964. American spiders of the genus Phoroncidia (Araneae: Theridiidae). Bulletin of the Museum of Comparative Zoology at Harvard College 131: 65-86. 
Marusik Y.M. \& Zamani A. 2015. The spider family Filistatidae (Araneae) in Iran. ZooKeys 516: $123-$ 135. http://dx.doi.org/10.3897/zookeys.516.10146

Nixon K.C. 2002. Winclada, version 1.00.08. Program and documentation. Available from http://www. cladistics.com/wincDownload.htm [accessed 21 Nov. 2015]

Panhuis T.M. \& Wilkinson G.S. 1999. Exaggerated male eye span influences contest outcome in stalkeyed flies (Diopsidae). Behavioral Ecology and Sociobiology 46 (4): 221-227. http://dx.doi.org/10.1007/ $\underline{\mathrm{s} 002650050613}$

Platnick N.I. \& Dupérré N. 2009. The American goblin spiders of the new genus Escaphiella (Araneae, Oonopidae). Bulletin of the American Museum of Natural History 328: 1-151. http://dx.doi. org/10.1206/679.1

Platnick N.I. \& Dupérré N. 2011. The Andean goblin spiders of the new genera Paradysderina and Semidysderina (Araneae, Oonopidae). Bulletin of the American Museum of Natural History 364: 1-121. http://dx.doi.org/10.1206/771.1

Platnick N.I., Dupérré N., Berniker L. \& Bonaldo A.B. 2013. The goblin spider genera Prodysderina, Aschnaoonops, and Bidysderina (Araneae, Oonopidae). Bulletin of the American Museum of Natural History 373: 1-102. http://dx.doi.org/10.1206/822.1

Schaible U., Gack C. \& Paulus H.F. 1986. Zur Morphologie, Histologie und biologischen Bedeutung der Kopfstrukturen männlicher Zwergspinnen (Linyphiidae, Erigoninae). Zoologische Jahrbücher. Abteilung für Systematik, Ökologie und Geographie der Tiere 113: 389-408.

Vanacker D., Maes L., Pardo S., Hendrickx F. \& Maelfait J.-P. 2003. Is the hairy groove in the gibbosus male morph of Oedothorax gibbosus (Blackwall 1841) a nuptial feeding device? Journal of Arachnology 31: 309-315. http://dx.doi.org/10.1636/s02-06

Wilkinson G.S. \& Dodson G.N. 1997. Function and evolution of antlers and eye stalks in flies. In: Choe J.C. \& Crespi B.J. (eds) The Evolution of Mating Systems in Insects and Arachnids: 310-328. Cambridge University Press, Cambridge.

World Spider Catalog. 2015. World Spider Catalog. version 16.5. Natural History Museum Bern. Available from http://wsc.nmbe.ch [accessed 17 Aug. 2015]

Zeil J., Nalbach G. \& Nalbach H.-O. 1986. Eyes, eye stalks and the visual world of semi-terrestrial crabs. Journal of Comparative Physiology A 159 (6): 801-811. http://dx.doi.org/10.1007/BF00603733

Manuscript received: 24 August 2015

Manuscript accepted: 13 October 2015

Published on: 28 December 2015

Topic editor: Rudy Jocqué

Desk editor: Charlotte Thionois

Printed versions of all papers are also deposited in the libraries of the institutes that are members of the EJT consortium: Muséum national d'Histoire naturelle, Paris, France; Botanic Garden Meise, Belgium; Royal Museum for Central Africa, Tervuren, Belgium; Natural History Museum, London, United Kingdom; Royal Belgian Institute of Natural Sciences, Brussels, Belgium; Natural History Museum of Denmark, Copenhagen, Denmark. 
Appendix 1. Data matrix for cladistic analysis. Taxa are arranged as in the cladogram in Fig. 1. Terminals and characters are detailed in Appendices 2 and 3. - = non-applicable; ? = unknown or coding ambiguous. This matrix is available online at www.pholcidae.de/matrices.html

Quamtana sp.

Pholcus phalangioides

Pholcus debilis

Pholcus phui

Pholcus diopsis

Pholcus atrigularis

Pholcus minang

Pa. Bor 96

Pa. Bor 11

Pa. bako

Pa. Bor 78

Pa. sedgwicki

Pa. iban

Pa. nigrifrons

Pa. Bor 100

Pa. Bor 109

Pa. cavicola

Pa. alba

Pa. mirabilis

Pa. madang

Pa. dubia

Pa. lanthana

Pa. malagos Huber sp. nov.

$P a$. casaroro Huber sp. nov.

$P a$. camiguin Huber sp. nov.

$P a$. hamiguitan Huber sp. nov.

Pa. isarog Huber sp. nov.

$P a$. dinagat Huber sp. nov.

Pa. marilog Huber sp. nov.

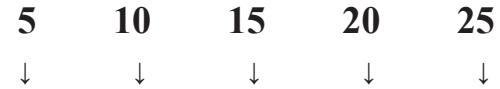

01--0000000-000-0001000--0

01--0000000-000-0000000--0

01--0000000-000-0000000--0

01--001-0010000-0001000--0

$00000001000-000-0000000--0$

$00000001000-000-0000000--0$

$00000001000-000-0000000--0$

$00000001001000100001000--0$

$00000001001100100001000--0$

$00000001001100100001000--1$

$00000001001100100001000--1$

0000000100110010001100 ????

01--0001001100100011000--1

01--0001001100110011000--1

01--0001001100100111000--1

01--0001001100100111000--1

0010001-000-01???001?0100?

0010001-000-11110001001000

0010001-000-11110001001000

0010001-000-11110001001000

0010001-000-11110001001000

01--001-000-01101001011000

0010001-100-01101001011001

1011001-100-01101001011000

1011001-100-01101001011000

0000001-000-11001001011000

0010011-000-000-1001111100

0010111-010-000-1001111110

0010111-010-000-1001111110 
Appendix 2. Terminal taxa scored for the cladistic analysis, with origin and depository. Taxa are arranged as in the cladogram in Fig. 1. Collection codes used in this appendix only: AMNH = American Museum of Natural History, New York; IRSB = Institut Royal des Sciences Naturelles de Belgique, Brussels; MZPW = Museum of the Institute of Zoology, Polish Academy of Science, Warsaw; QMB = Queensland Museum, Brisbane; RMNH = Netherlands Centre for Biodiversity Naturalis, Leiden.

\section{Outgroups}

Quamtana sp.: for the present matrix, all known species of Quamtana Huber, 2003 share the same coding. For this reason, no particular species is specified.

Pholcus phalangioides (Fuesslin, 1775): Germany, Bonn (ZFMK)

Pholcus debilis (Thorell, 1899): Cameroon, Mt. Koupé (ZFMK)

Pholcus phui Huber, 2011: Thailand, Hala Bala WS (ZFMK)

Pholcus diopsis Simon, 1901: Thailand, Wat Kuhapimuk (ZFMK)

Pholcus atrigularis (Simon, 1901): Malaysia, Ulu Dong (ZFMK)

Pholcus minang Huber, 2011: Indonesia, Sumatra, Kerinci N.P. (RMNH)

\section{Panjange}

Pa. Bor 96: Malaysia, Sarawak, Pueh (ZFMK)

$P a$. Bor 11: Malaysia, Sarawak, Niah (ZFMK)

Pa. bako Huber, 2011: Malaysia, Sarawak, Bako (RMNH)

$P a$. Bor 78: Malaysia, Sarawak, Kapit (ZFMK)

Pa. sedgwicki Deeleman-Reinhold \& Platnick, 1986: Malaysia, Sarawak, nr Kapit (AMNH)

Pa. iban Huber, 2011: Malaysia, Sarawak, Semengoh (ZFMK)

Pa. nigrifrons Deeleman-Reinhold \& Deeleman, 1983: Indonesia, Kalimatan, Sepaku (RMNH)

$P a$. Bor 100: Malaysia, Sarawak, Penrissen (ZFMK)

$P a$. Bor 109: Malaysia, Sarawak, Kubah (ZFMK)

Pa. cavicola Deeleman-Reinhold \& Deeleman, 1983: Indonesia, Sulawesi, nr Camba (RMNH)

$P a$. alba Deeleman-Reinhold \& Deeleman, 1983: Indonesia, Sulawesi (RMNH)

Pa. mirabilis Deeleman-Reinhold, 1986: Australia, Queensland, Gordon Creek (QMB)

Pa. madang Huber, 2011: Papua New Guinea, Baiteta (IRSB)

Pa. dubia (Kulczyński, 1911): Indonesia, New Guinea (RMNH, MZPW)

Pa. lanthana Deeleman-Reinhold \& Deeleman, 1983: Philippines, Luzon, Mt. Isarog (ZFMK)

$P a$. malagos Huber sp. nov.: Philippines, Mindanao, Malagos (ZFMK)

$P a$. casaroro Huber sp. nov.: Philippines, Negros, Casaroro Falls (ZFMK)

$P a$. camiguin Huber sp. nov.: Philippines, Camiguin, Katibawasan Falls (ZFMK)

$P a$. hamiguitan Huber sp. nov.: Philippines, Mindanao, Mt. Hamiguitan (ZFMK)

Pa. isarog Huber sp. nov.: Philippines, Luzon, Mt. Isarog (ZFMK)

$P a$. dinagat Huber sp. nov.: Philippines, Dinagat, Paragua (ZFMK)

Pa. marilog Huber sp. nov.: Philippines, Mindanao, Baganihan (ZFMK) 
Appendix 3. Characters scored for cladistic analysis.

\section{Male prosoma}

1. Eye stalks: (0) short, i.e. up to $3 \times$ as long as wide; (1) long, i.e. more than $6 \times$ as long as wide. Extremely long eye stalks are shared by Pa. casaroro Huber sp. nov. and Pa. camiguin Huber sp. nov. (Figs 28, 35).

2. Pointed processes arising from near PME: (0) present (e.g., Figs 17, 28, 66); (1) absent. Such processes occur in Panjange and in several species currently included in Pholcus (Huber 2011). They are thus considered plesiomorphic for Panjange, where they have been secondarily lost in $P a$. lanthana and within the nigrifrons group.

3. Ocular pointed processes, shape: (0) straight or slightly curved (Fig. 66); (1) strongly curved or hooked (Figs 48, 87). Strongly curved ocular processes unite the Panjange cavicola and lanthana groups. In Pa. hamiguitan Huber sp. nov. the processes are considered secondarily straight.

4. Ocular pointed processes, tips: (0) not contacting each other; (1) contacting and parallel to each other. The unique configuration of the two processes forming an apparent functional unit (the dorsal one lying in a groove of the ventral one) is shared by Pa. casaroro Huber sp. nov. and Pa. camiguin Huber sp. nov. (Figs 48, 49). The processes are similar in Pa. bukidnon Huber sp. nov. (Fig. 90) but there the tips lie simply side by side.

5. Ocular area, strong hairs on frontal side: (0) absent; (1) present. Strong hairs (Fig. 84; in addition to spines more distally on the clypeus, see character 6) are shared by Pa. dinagat Huber sp. nov. and Pa. marilog Huber sp. nov.

6. Clypeus spines: (0) absent; (1) present. The presence of such spines (Figs 84, 85) is a synapomorphy of $P a$. isarog Huber sp. nov., Pa. dinagat Huber sp. nov., and $P a$. marilog Huber sp. nov.

7. Distal cheliceral apophyses: (0) present; (1) absent. The absence of distal cheliceral apophyses unites the Panjange cavicola and lanthana groups.

8. Distal cheliceral apophyses, shape: (0) simple; (1) bipartite. A bipartite apophysis characterizes the Panjange nigrifrons group as well as several outgroup species (Pholcus diopsis; Pholcus atrigularis; Pholcus minang) (e.g., figs 476, 640, 664, 690 in Huber 2011). It is thus considered plesiomorphic for Panjange.

\section{Male palps}

9. Pedipalp asymmetry: (0) absent; (1) present. Asymmetry is here interpreted as having evolved once, uniting three species in the southern Philippines ( $P a$. malagos Huber sp. nov., Pa. casaroro Huber sp. nov., and Pa. camiguin Huber sp. nov.).

10. Trochanter, retrolatero-ventral apophysis: (0) absent or with simple tip; (1) with complex bifid tip and subdistal prolateral side-branch (Figs 75, 80). A complex retrolatero-ventral apophysis unites $P a$. dinagat Huber sp. nov. and $P a$. marilog Huber sp. nov.

11. Femur ventral apophysis: (0) absent; (1) present. A distinct ventral process (rather than just a bulging area) characterizes the Panjange nigrifrons group (e.g., figs 470, 490 in Huber 2011) and is here interpreted to have evolved independently in Pholcus phui.

12. Femur ventral apophysis, shape: (0) about as long as wide and not directed toward distal; (1) longer than wide and directed toward distal (e.g., figs 470, 490 in Huber 2011). A relatively long apophysis unites most species of the Panjange nigrifrons group.

13. Tibia shape: (0) not elongated, i.e. less than $3 \times$ as long as wide; (1) elongated, i.e. more than $3 \times$ as long as wide. An elongated tibia characterizes most species of the Panjange cavicola group (except $P a$. cavicola itself) and has independently evolved in a much more extreme way in Pa. hamiguitan (Figs 64, 65).

14. Tarsal elongation: (0) absent or short (less than $1.5 \times$ as long as wide at basis) (Figs 70, 75, 80); (1) long (longer than $2 \times$ as long as wide) (e.g., Figs 19, 39, 65). A strong elongation of the tarsus unites the Panjange cavicola and lanthana groups, but a reversal occurs within the lanthana group, uniting $P a$. isarog Huber sp. nov., Pa. dinagat Huber sp. nov., and Pa. marilog Huber sp. nov. 
15. Procursus ridges: (0) absent; (1) present (e.g., Figs 18, 26, 52). A series or parallel ridges on the procursus has been proposed as a synapomorphy of Panjange before (Huber 2011). In some of the newly described species, these ridges are (apparently secondarily) either indistinct or even absent (Pa. hamiguitan Huber sp. nov., Pa. isarog Huber sp. nov., Pa. dinagat Huber sp. nov., and Pa. marilog Huber sp. nov.).

16. Procursus ridges, number: (0) many; (1) only 2-3. Many ridges occur in most species of the Panjange nigrifrons group (e.g., figs 470, 490 in Huber 2011) except in Pa. nigrifrons itself and in several species of the lanthana group (e.g., Figs 18, 26, 52). This condition is thus interpreted to be plesiomorphic for Panjange. Other than in Pa. nigrifrons, a reduction has occurred in the cavicola group (the condition in $P a$. cavicola is not clear).

17. Procursus ventral process: (0) absent; (1) present. This process seems to unite the Panjange lanthana group. It is very distinct in some species (Pa. lanthana, see fig. 437 in Huber 2011; Pa. casaroro Huber sp. nov., Fig. 27; Pa. hamiguitan Huber sp. nov., Fig. 65; Pa. isarog Huber sp. nov., Fig. 70; $P a$. dinagat Huber sp. nov., Fig. 75; Pa. marilog Huber sp. nov., Fig. 80), but indistinct in others (Pa. malagos Huber sp. nov., Fig. 19; Pa. camiguin Huber sp. nov., Fig. 42).

18. Procursus retrolateral transversal sclerite: (0) absent; (1) present. A distinctive transversal sclerite characterizes two undescribed species closely related to Panjange nigrifrons.

19. Procursus tip, shape: (0) not flat and widened; (1) flat and widened. A flat and widened procursus tip (e.g., fig. 470 in Huber 2011; fig. 3 in Deeleman-Reinhold \& Platnick 1986) unites several species of the Panjange nigrifrons group.

20. Uncus on genital bulb: (0) absent; (1) present. Most Pholcus species have a distinct bulbal sclerite in addition to the appendix, the so-called uncus. Since Panjange seems to be nested within a currently paraphyletic Pholcus (Huber 2011), the absence of an uncus in Panjange is here considered to be secondary. This reduction has been suggested as a potential synapomorphy of Panjange before (Huber 2011), but Pholcus phui (and other species not included in the matrix) share this absence and may be closer to Panjange than suggested by the cladogram in Fig. 1.

21. Toothed sclerotized process of proximal bulbal sclerite: (0) absent; (1) present. This sclerite (Figs 69, $74,79)$ unites three species in the Panjange lanthana group ( $P a$. isarog Huber sp. nov., Pa. dinagat Huber sp. nov., and $P a$. marilog Huber sp. nov.). It reminds of an uncus but is here considered a novel structure because it is situated behind the embolus (in prolateral view), while the uncus is situated in front of the embolus.

22. Embolus, direction: (0) parallel to appendix; (1) in opposite direction than appendix. An embolus that points in the opposite direction than the appendix (e.g., Figs 18, 64, 69) is a highly unusual character and is here considered a (strong) synapomorphy of the Panjange lanthana group.

\section{Female genitalia}

23. Scape: (0) absent or short, not strongly folded; (1) present, strongly folded and extensible. A strongly folded and extensible scape (e.g., Figs 22, 67, 72) unites the Panjange cavicola and lanthana groups.

24. Scape, direction: (0) toward posterior; (1) toward anterior. Three species of the Panjange lanthana group (Pa. isarog Huber sp. nov., Pa. dinagat Huber sp. nov., Pa. marilog Huber sp. nov.) are united by a scape that is directed toward anterior (Figs 72, 77, 82).

25. Scape, widening: (0) absent; (1) present. Two species of the Panjange lanthana group (Pa. dinagat Huber sp. nov., $P$ a. marilog Huber sp. nov.) are united by a scape that has a distinctive widened area at about half its length (Figs 77, 82).

26. Female internal genital folds: (0) absent or weakly developed; (1) strongly developed. Most species of the Panjange nigrifrons group share a system of strongly developed folds of unknown significance in the female internal genitalia (e.g., figs 473 and 492 in Huber 2011). 